\title{
Diversidade, taxonomia e distribuição por estados brasileiros das famílias Bartramiaceae, Brachytheciaceae, Bryaceae, Calymperaceae, Fissidentaceae, Hypnaceae e Leucobryaceae (Bryophyta) da Estação Científica Ferreira Penna, Caxiuanã, Pará, Brasil
}

\author{
Eryka de Nazaré Rezende MORAES ${ }^{1}$, Regina Célia Lobato LISBOA²
}

\begin{abstract}
RESUMO
Foi realizado o inventário das espécies de musgos (Bryophyta) da Estação Científica Ferreira Penna, município de Melgaço, estado do Pará. Esta estação possui $85 \%$ de sua área ocupada por mata de terra firme, bem conservada. Sua vegetação de fanerógamas já está relativamente estudada. Porém o estudo dos musgos está avançando agora com este trabalho. Além de inventariar as espécies de musgos ocorrentes na área, outros objetivos são ampliar a distribuição geográfica das espécies ainda não referidas para a região, registrar o tipo de substrato e ecossistema onde elas ocorrem. Foram identificadas 84 espécies, 37 gêneros e 19 famílias. Esse trabalho é parte dos estudos realizados com os musgos da ECFPn, tratando apenas das 47 espécies pertencentes às famílias Bartramiaceae, Brachytheciaceae, Bryaceae, Calymperaceae, Fissidentaceae, Hypnaceae e Leucobryaceae. Para cada táxon foram citados, herbário, referências de descriçóes, comentários com as características diagnósticas, habitats, distribuição geográfica brasileira e material examinado. São novas referências para Amazônia Brasileira, Fissidens pauperculus M.Howe e Octoblepharum costatum H.A.Crum e para o estado do Pará, Syrrhopodon incompletus Schwägr. var. berteroanus (Brid.) W.D.Reese e Leucobryum crispum Müll.Hal.
\end{abstract}

PALAVRaS-CHAVE: Briófitas, Município de Melgaço, Amazônia, Biodiversidade.

\section{Diversity, taxonomy and distribution for Brazilian states of the families Bartramiaceae, Brachytheciaceae, Bryaceae, Calymperaceae, Fissidentaceae, Hypnaceae and Leucobryaceae (Bryophyta) of the Scientific Station Ferreira Penna, Caxiuanã, Pará, Brazil)}

\begin{abstract}
The inventory of the species of mosses (Bryophyta) was conducted in the Scientific Station Ferreira Penna, municipality of Melgaço, state of Pará. This station possesses $85 \%$ of its area of well conserved, terra-firme vegetation. Although the phanerogams are relatively well studied, the mosses are only now moving forward with this work. Besides inventorying the species of mosses inhabiting the area, other objectives are to expand knowledge regarding the geographical distribution of the species reported for the area, and to register the substratum type and ecosystem where they occur. There were identified 84 species, 37 genera and 19 families. This work is part of a series of studies accomplished with the mosses of ECFPn, just treating the 47 species belonging to the families Bartramiaceae, Brachytheciaceae, Bryaceae, Calymperaceae, Fissidentaceae, Hypnaceae and Leucobryaceae. For each táxon they were mentioned place-type, herbarium, references of descriptions, comments regarding morphological characteristics, Brazilian geographical distribution and examined material. Herein we include new references for Amazonian Brazilian, Fissidens pauperculus M.Howe and Octoblepharum costatum H.A.Crum and for the state of Pará, Syrrhopodon incompletus Schwägr. var. berteroanus (Brid.) W.D.Reese and Leucobryum crispum Müll.Hal.
\end{abstract}

KEYWORDS: Bryophytes, Municipality of Melgaço, Amazon, Biodiversity.

Museu Paraense Emílio Goeldi. E-mail: enrmoraes@yahoo.com.br

2 Museu Paraense Emílio Goeldi. E-mail: regina@museu-goeldi.br 


\section{INTRODUÇÃO}

As briófitas são plantas que apresentam ampla distribuição geográfica, mas são especialmente predominantes nas regiôes tropicais e subtropicais (Lemos-Michel, 2001). Geralmente desenvolvem-se agrupadas em tufos, formando almofadas ou tapetes extensos, às vezes de grandes dimensóes. Podem ser encontradas nos habitats mais diversos, colonizando diferentes substratos, tendo preferência por lugares úmidos e sombrios devido à dependência da água para se reproduzir (Lisboa, 1993). Entretanto, também ocorrem em locais secos e expostos a intempéries.

O papel ecológico das briófitas é significativo, sobretudo em ecossistemas florestais, onde são importantes componentes da biomassa; interceptam e retém a água da chuva, protegendo o solo contra a erosão; são plantas pioneiras, possibilitando o estabelecimento de outros vegetais e servindo de microhabitat para pequenos organismos; servem como bioindicadores da qualidade do ar, água e solo; alguns indivíduos sáo indicadores de metais, poluição e outros possuem um grande potencial econômico e como fontes de substâncias importantes para o ser humano (Ando \& Matsuo, 1984; Frahm \& Kirchhoff, 2002; Glime \& Saxena, 1991; Gradstein \& Pócs, 1989; Lisboa, 1993; Lisboa \& Ilkiu-Borges, F. 1996; Pôrto et al., 2004; Schofield, 1985; Zartman, 2003).

De acordo com Gradstein \& Pócs (1989), estima-se que as florestas tropicais tenham mais espécies de briófitas que qualquer outro grande ecossistema no mundo devido ás condiçôes climáticas favoráveis e uma grande diversidade de microhabitats. Costa (2003) relata para Amazônia brasileira uma diversidade alta com 514 espécies de briófitas, sendo 264 espécies de musgos e 250 de hepáticas. Segundo a autora apenas alguns estados da Amazônia brasileira tem sido mais estudados quanto à flora briofítica. Entre estes se destaca o estado do Pará.

Quanto à diversidade dos musgos, Churchill (1998) em seu catálogo da Amazônia relata uma diversidade de 133 espécies para o estado do Pará. Entretanto, ao longo dos anos, Lisboa e colaboradores vem contribuindo para um maior conhecimento, o qual alcança para o Estado 149 espécies, citadas em diversos trabalhos, como os de Lisboa \& IlkiuBorges, F. (1996); Souza \& Lisboa (2006); Santos \& Lisboa (2003); Lisboa et al. (1998 e 1999); Lisboa \& Ilkiu-Borges (1995, 1997a, 1997b, 2001 e 2007); Lisboa \& Lima (1997); Moraes \& Lisboa (2006); Pinheiro et al. (1989); Lisboa \& Santos (2005); Ilkiu-Borges et al. (2004); Lisboa \& Yano (1987), Lisboa \& Maciel (1994); Lisboa (1994); Lisboa (1984); Souza \& Lisboa (2005); Lisboa \& Nazaré (1997, 2002); Lisboa \& Ilkiu-Borges (2007).

Entretanto há vastas regióes do estado que ainda não foram coletadas e outras cuja brioflora de musgos ainda está sendo estudada. Nesse contexto, está inserida a Floresta Nacional de Caxiuaná, localizada na Amazônia Oriental, estado do Pará, sendo uma reserva natural de proteçáo ambiental que contribui para a conservação da biodiversidade. Considerando que essa região ainda possui $85 \%$ da cobertura vegetal original e possui a maioria dos ecossistemas mais representativos da regiáo amazônica (Ruivo et al., 2002) possivelmente o número de espécies de briófitas, incluindo novas ocorrências para Amazônia Brasileira, deve aumentar com novos estudos florísticos e taxonômicos.

Lisboa \& Nazaré $(1997,2002)$ iniciaram os estudos sobre a flora de musgos na Estação Científica de Caxiuanã e identificaram 12 famílias, distribuídas em 19 gêneros. $\mathrm{Na}$ ocasião as espécies Calymperes guildingii, Taxithelium pluripunctatum, Potamium lonchophyllum e Trichosteleum intricatum, foram citados pela primeira vez para o estado do Pará, Entretanto devido à grande quantidade de amostras coletadas e não identificadas os resultados ficaram incompletos.

Este trabalho dá continuidade aos estudos realizados sobre os musgos da "Estação Científica Ferreira Penna" (ECFPn), e trata apenas das famílias Bartramiaceae, Brachytheciaceae, Bryaceae, Calymperaceae, Fissidentaceae, Hypnaceae e Leucobryaceae e tem como objetivo inventariar as espécies de musgos desta localidade, registrar o tipo de substrato e ecossistema onde elas ocorrem, ampliar a distribuição geográfica daquelas ainda não referidas para a regiáo, como também enriquecer a coleção de briófitas do Herbário do Museu Paraense Emílio Goeldi (MG).

\section{MATERIAL E MÉTODOS}

\section{DESCRIÇÃO DA ÁREA DE ESTUDO}

A Estação Científica Ferreira Penna (ECFPn) está inserida nos domínios da Floresta Nacional de Caxiuanã ( $1^{0} 42^{\prime} 30^{\prime \prime}$ $\mathrm{S}$ e $51^{\circ} 31^{\prime} 45^{\prime}$ W) - uma unidade de conservaçáo federal, gerenciada pelo IBAMA, ocupando áreas dos municípios de Melgaço e Portel, estado do Pará. - A ECFPn localiza-se em Melgaço, distando cerca de $400 \mathrm{~km}$ SW de Belém em linha reta. Limita-se ao Norte pelo divisor de águas entre as bacias dos rios Caxiuanã e Amazonas, ao Sul seu limite natural é o rio Caxiuaná, a Leste a baia de Caxiuanã e o igarapé do Laranjal e a Oeste com o igarapé Grande (Lisboa, P. 2002).

De acordo com Lisboa, P. et al. (1997) esta área apresenta ecossistemas como floresta densa de terra firme, ocupando cerca de $85 \%$ do total da área; florestas de inundação (várzea e igapó), vegetação savanóide (campo hidromórfico) e vegetação secundária (capoeira). Segundo a classificação de Köppen, o clima da regiâo e do tipo Am, caracterizando-se como clima tropical quente, com um período mais chuvoso de dezembro a maio e um período mais seco de agosto a novembro. A temperatura média anual é de $26,7^{\circ} \mathrm{C}$. A umidade relativa do 
ar fica em torno de $87 \%$ (Costa \& Moraes, 2002). Os solos são classificados em Latossolos Amarelo de origem terciária, com textura argilo-arenosa (Almeida et al., 1993). O relevo é plano sem grandes elevaçóes (Brasil, 1974).

\section{COLETA E IDENTIFICAÇÃO DO MATERIAL}

As amostras foram coletadas nos diferentes tipos de vegetação da Estação Científica Ferreira Penna (ECFPn) entre os anos de 1992 a 2002 e outubro de 2004. O total de 600 amostras foram estudadas. As espécies foram classificadas de acordo com o substrato onde foram encontradas, segundo Robbins (1952): corticícola (tronco de árvore viva), epíxila (tronco morto ou em decomposição), epífila (folhas vivas), rupícula (pedras), terrestre (solo ou litteira). Algumas espécies foram coletadas em cupinzeiro ou concreto (rocha ou solo pavimentado). O método de coleta utilizado foi o de Lisboa (1993). As identificaçôes foram baseadas nas chaves e principalmente nos trabalhos de Florschütz (1964); Florschütz-De Waard (1986 e 1996); Florschütz-De Waard \& Veling (1996); Griffin III (1979); Lisboa (1993); Peralta (2005); Pursell (1997); Reese (1961, 1978, 1993); Veling (1996); Yano (1992) e Zielman (1996). Algumas espécies necessitaram de comparação com material identificado por especialistas depositadas no Herbário do Museu Paraense Emílio Goeldi (MG).

O sistema de classificação adotado foi o de Buck \& Goffinet (2000), exceto a família Leucobryaceae que está de acordo com Vitt (1984). A terminologia briológica foi padronizada com base na Versão Brasileira do Glossarium Polyglottum Bryologiae (Luizi-Ponzo et al., 2006).

Para cada espécie foram citadas referências sobre descriçóes e ilustraçóes; comentários com características diagnósticas das espécies relacionadas, descrição detalhada apenas para novas ocorrências; notas ecológicas sobre habitats; distribuição geográfica brasileira segundo IBGE e material examinado (somente três amostras por espécie). A distribuição geográfica foi baseada nos trabalhos de Câmara (2002); Câmara et al. (2003); Castro et al. (2002); Churchill (1998); Costa (2003); Costa \& Silva (2003); Lisboa \& Nazaré (1997); Molinaro \& Costa (2001); Moraes (2006); Moraes \& Lisboa (2006); Oliveira-e-Silva \& Yano (2000); Peralta (2005); Pôrto et al., (1994); Reese (1993); Visnadi (2004; 2005); Yano (1981; 1989; 1992, 1994, 1995, 2004, 2006); Yano \& Bastos (1994); Yano \& Câmara (2004); Yano \& Colletes (2000) e Yano \& Peralta (2004, 2008). O material foi incorporado ao herbário "João Murça Pires" (MG), do Museu Paraense Emílio Goeldi.

\section{RESULTADOS}

Neste trabalho são apresentadas as famílias Bartramiaceae, Brachytheciaceae, Bryaceae, Calymperaceae, Fissidentaceae,
Hypnaceae e Leucobryaceae, totalizando 47 espécies. Quatro dessas espécies são novas ocorrências, sendo duas para Amazônia Brasileira (Fissidens pauperculus M.Howe e Octoblepharum costatum H.A.Crum) e duas para o Estado do Pará (Syrrhopodon incompletus Schwägr. var. berteroanus (Brid.) W.D. Reese. e Leucobryum crispum Müll.Hal.). Os táxons apresentados a seguir estão em ordem alfabética de família e gênero.

\section{BARTRAMIACEAE Schwägr.}

Philonotis gracillima Ångstr. Öefv. K. Sv. Vet. - Ak. Förh. 33 (4): 17. 1876.

Descrição e ilustração: Crum \& Anderson (1981) e Souza \& Lisboa (2005).

Comentários: Filídios não falcados; ápice obtuso ou arredondado; costa terminando bem abaixo do ápice (subpercurrente). Difere das espécies $P$. uncinata (Schwägr) Brid, que possui filídios falcados no topo dos caulídios, com ápice agudo e costa excurrente e P. glaucescens (Hornsch.) Broth., com filídios não falcados, ápice agudo e costa percurrente (Lisboa, 1993).

Habitat: A família tem preferência por ambientes úmidos, como margens de rios, solos e rochas (Souza, 2004). Em Caxiuanã foi coletada uma vez no solo, sobre bloquetes.

Distribuição geográfica: AC, AM, BA, DF, ES, MG, MS, PA, PR, PE, PI, RO, RJ, SC e SP. Primeira referência para a área de Caxiuanã.

Material examinado. BRASIL. Pará: Município de Melgaço, FLONA de Caxiuanã, Estação Científica Ferreira Penna, na sede, 1.V.1995, R. Lisboa, et al. 5111 (MG).

\section{BRACHYTHECIACEAE Schimp.}

Zelometeorium patulum (Hedw.) Manuel, J. Hattori Bot. Lab. 43: 118. 1977.

Descrição e ilustração: Florschutz (1964) como Meteoriopsis patula (Hedw.) Broth., e Visnadi (2002).

Comentários: A espécie é variável em hábito e forma, possui filídios lanceolado-acuminados, patentes; ápice piliforme ou acuminado; costa única; margem serreada. Porém é facilmente reconhecida pela base cordada, amplexicaule nos filídios do caulídio e parcialmente nos filídios dos ramos.

Habitat: Ramos de arbustos e árvores, em baixas altitudes a moderadas elevaçóes (150 a $1.400 \mathrm{~m}$ alt.) (Sharp et al., 1994). Em troncos vivos ou mortos e folhas.

Distribuição geográfica: AC, AL, AM, AP, ES, GO, MG, MS, MT, PA, PE, PR, RJ, RO, RR, RS, SC e SP. Primeira referência para a área de Caxiuanã.

Material examinado. BRASIL. Pará: Município de Melgaço, FLONA de Caxiuanã, Estação Científica Ferreira Penna, Inv. 12, Igarapé Retiro, floresta de terra firme, 
1.XI.1996, R. Lisboa, et al. 6026, 6059(MG); ibidem, Igarapé Laranjal, mata de várzea, 28.X.2004, E. Moraes 176 (MG).

BRYACEAE Schwägr.

Gemmabryum coronatum (Schwägr.) J.R. Spence \& H.P. Ramsay Phytologia 87: 66. 2005 (Segundo Spence \& Ramsay, 2005).

Descrição e ilustração: Lisboa (1993), Peralta (2005) como Bryum coronatum Schwaegr

Comentários: Filídios lanceolados, esquarrosos; ápice acuminado; costa longo-excurrente; margem recurvada na parte inferior, com borda indistinta; seta vermelha, com cápsula pêndula, colo curto e truncado.

Habitat: É uma espécie aparentemente invasora (Ochi, 1980). Cresce em solo húmido até relativamente seco, locais abertos até pouco sombreados. Foi coletada sobre muro de concreto, em solo argilo-pedregoso, tendo preferência pelo habitat terrestre.

Distribuição geográfica: AC, AM, BA, DF, FN, GO, MA, MG, MT, PA, PB, PE, PR, RJ, RO, RR, RS, SC e SP.

Material examinado. BRASIL. Pará: Município de Melaço, FLONA de Caxiuanã, Estação Científica Ferreira Penna, na sede, 01.V.1995, R. Lisboa, et al. 5117 (MG); ibidem, 4.V.1995, R. Lisboa, et al. 5248, 5250 (MG).

\section{CALYMPERACEAE Kindb.}

Calymperes afzelii Sw., Jahrb, Gewächsk. 1 (3): 1. 1818.

Descrição e ilustração: Lisboa (1993); Peralta (2005) e Reese (1993).

Comentários: Filídios com propágulos, gemas surgindo apenas na superfície ventral da costa próximo ao ápice; teníola proeminente; células cancelinas não mamilosas; margem superior duplamente serreada próximo do ápice e inteiras na regiâo basal. É similar a C. erosum Müll.Hal., porém, nesta última, as gemas surgem em todo o ápice, a costa e as células distais das cancelinas são mamilosas com a margem superior grosseiramente serreada próximo do ápice e inteiras na regiâo basal.

Habitat: Espécie típica de florestas de baixas altitudes (primárias, secundárias e pântanos), geralmente encontrado na base de troncos vivos, apodrecidos, sobre lianas e superfície de rochas (granitos ou arenito) (Edwards, 1980).

Distribuição geográfica: AC, AM, BA, ES, MG, MS, MT, PA, PB, PE, RJ, RO, RR, SC e SP.

Material examinado. BRASIL. Pará: Município de Melaço, FLONA de Caxiuanã, Estação Científica Ferreira Penna, baía de Caxiuanã, várzea ao redor da campina em frente à Baía de Caxiuanã, 4.XI.1996, R. Lisboa, et al. 6122, 6130 (MG); ibidem, Igarapé Curuá, mata de igapó, 20.X.2004, E. Moraes 45 (MG).

Calymperes erosum Müll.Hal., Linnaea 21: 182. 1848.

Descrição e ilustração: Reese (1961); Lisboa (1993) e Peralta (2005).

Comentários: Esta espécie é semelhante a $C$. afzelii, diferenciando desta pelas cancelinas formando ângulo agudo com a costa e muito mamilosas na altura dos ombros; teníolas alcançando quase todo ápice do filídio; células superiores irregulares. Também pode ser confundida com C. pallidum Mitt., diferindo desta pelas cancelinas e costa menos papilosa e em corte transversal possuir feixes definidos de estereídes (Reese, 1961).

Habitat: Sobre tronco de árvore viva ou em decomposição, raramente sobre pedras, em locais úmidos, como florestas altas perto de rios ou ambientes mais abertos, tipo savanas até 500m de altitude (Lisboa, 1993). Em Caxiuanã foi coletada também em árvore com cupim.

Distribuição geográfica: AC, AM, AP, BA MG, MT, PA, PB, PE, RJ, RO e RR.

Material examinado. BRASIL. Pará: Município de Melgaço, FLONA de Caxiuanã, Estação Científica Ferreira Penna, Igarapé Curuá, mata de igapó, 20.X.2004, E. Moraes 53 (MG); ibidem, Igarapé Arauá, floresta de terra firme, na trilha 01/1000m, 22.X.2004, E. Moraes 113 (MG); ibidem, Igarapé Arauá, mata de igapó, 22.X.2004, E. Moraes 124 (MG).

Calymperes guildingii Hook. \& Grev., Edinburgh J. Sci. 3: 223.1825.

Descrição e ilustração: Reese (1961, 1993) e Florschütz (1964).

Comentários: Esta espécie pode ser confundida com C. bartramii Reese e C. nicaraguense Renauld \& Cardot, porém diferencia-se pelas margens dos filídios dobradas para dentro; teníolas com paredes grossas e sinuosas; as cancelinas finalizando em um ângulo agudo com a costa.

Habitat: Cresce em tufos firmes, geralmente sobre rochas, mas também sobre lianas, troncos de árvores vivas ou em decomposição, em humus e no solo (Reese, 1993). Em Caxiuanã foi coletada sobre folha.

Distribuição geográfica: AM, PA e RO.

Material examinado. BRASIL. Pará: Município de Melgaço, FLONA de Caxiuanã, Estação Científica Ferreira Penna, Igarapé Grande, margem esquerda, mata de várzea, 17.I.1993, R. Lisboa, et al. 2306, 2297 (MG); ibidem, Furo do Camuim, mata de várzea, 28.XI.2000, R. Lisboa \& $A$. Ilkiu-Borges 6959 (MG).

Calymperes levyanum Besch., Ann. Sci. Nat. Bot. Ser. 8, 1:290. 1896. 
Descrição e ilustração: Florschütz (1964) e Reese (1993).

Comentários: Gametófitos verdes, filídios pequenos; base obovalada; células unipapilosas, as medianas dispostas transversalmente. Essa espécie se assemelha a C. lonchophyllum Schwägr., porém C. levyanum apresenta filídios menores que $8,0 \mathrm{~mm}$ e as células superiores são papilosas, tornando-as obscuras, enquanto que $C$. lonchophyllum apresenta filídios maiores que $8,0 \mathrm{~mm}$ e as suas células são lisas e mais claras.

Habitat: Em troncos de árvores, sendo considerada uma espécie de ocorrência rara (Reese, 1993). Na área estudada foi exclusivamente corticícola.

Distribuição geográfica: AM, MT, PA. Primeira referência para área de Caxiuaná.

Material examinado. BRASIL. Pará: Município de Melgaço, FLONA de Caxiuanã, Estação Científica Ferreira Penna, Igarapé Grande, Inv. 9, floresta de terra firme, 13.XI.1995, R. Lisboa \& C. Silva 5330, 5382, 5385 (MG).

Calymperes lonchophyllum Schwägr., Spec. Musc. Suppl. 1 (2): 333, 98. 1816. Tipo: Guiana Francesa, Richard 38 (Holótipo, PC; Isótipo, G).

Descrição e ilustração: Florschütz (1964); Lisboa (1993) e Reese (1993).

Comentários: Filídios muito longos (10-20 mm comp.), lineares, crispados e tortuosos quando secos, lineares quando úmidos; base obovalada; células lisas, as medianas, tranversalmente alongadas. Pode ser confundida com $C$. venezuelanum (Mitt.) Reese e C. levyanum Besch, sendo que a primeira apresenta a lâmina interrompida acima dos ombros e a segunda apresenta as células superiores dos filídios densamente papilosas.

Habitat: Espécie principalmente corticícola, pode ocasionalmente ser encontrada sobre rocha e tronco morto (Reese, 1993). Em florestas com arenitos e granitos expostos, sobre palmeiras (Lisboa, 1993). Raramente sobre pedras e regióes costeiras (Florschütz, 1964). Reese (1961) resalta a ocorrência mais frequente em altitudes moderadas (ca. 300$600 \mathrm{~m})$. Ocorre com freqüência em Caxiuanã.

Distribuição geográfica: AC, AL, AM, AP, BA, ES, MA, MT, PA, PR, PE, RJ, RO, RR e SP.

Material examinado. BRASIL. Pará: Município de Melgaço, FLONA de Caxiuanã, Estação Científica Ferreira Penna, Igarapé Curuá, floresta de terra firme, 18.X.2004, E. Moraes 26 (MG); ibidem, mata de igapó, 20.X.2004, E. Moraes 48 (MG); ibidem, Igarapé Arauá, floresta de terra firme, 26.X.2004, E. Moraes 142 (MG).

Calymperes nicaraguense Renauld \& Cardot, Bull. Soc. Bot. Belg. 33 (2): 117. 1895.
Descrição e ilustração: Florschütz (1964), Lisboa (1993) e Reese (1993).

Comentários: Filídios com base muito alargada; cancelinas conspícuas e ombros pronunciados; teníolas fortes a quase ausentes; margens serreadas. Pode ser confundida com $C$. afzelli, diferenciando desta última por suas teníolas, na altura dos ombros, não estar evidentemente separada das células das margens (Florschütz, 1964).

Habitat: Em florestas e savanas, locais úmidos, sobre madeira em decomposição, sobre árvore viva (Lisboa, 1993). Tem preferência por pedras, sendo bem mais robustas que aquelas que crescem em árvores (Reese, 1979). Em Caxiuanã foi coletada uma vez, sobre casca de tronco vivo.

Distribuição geográfica: AM, AP, ES, MT, PA e RO. Primeira referência para a área de Caxiuanã.

Material examinado. BRASIL. Pará: Município de Melgaço, FLONA de Caxiuanã, Estação Científica Ferreira Penna, Furo do Camuim, floresta de terra firme, 24.XI.2000, R. Lisboa, et al. 6872 (MG).

Calymperes palisotii Schwägr., Spec. Musc. Suppl. 1 (2): 334.1816.

Descrição e ilustração: Florschütz (1964) como Calymperes richardii Müll.Hal., Reese (1993) e Peralta (2005).

Comentários: Apresenta características muito constantes, como filídios oblongo-ligulados; ápice largo e obtuso; base sem ombros, as cancelinas retangulares formando grande ângulo obtuso; teníolas intra-marginais, células superiores da lâmina claramente papilosas, largas, truncadas distalmente; presença freqüente de tufos de gemas no ápice. Segundo Peralta (2005) as teníolas são visíveis até à porção mediana-superior, células da lâmina mamilosas em ambos os lados, margem sem borda.

Habitat: Freqüente nas margens de ecossistemas alagados, como várzea (Lisboa et al., 1998). Reese \& Stone (1995) relatam para ecossistemas como mangues e pântanos na Austrália, indicando tolerância a ambientes alagados, alta intensidade de luz e temperatura. Segundo Florschütz (1964) é encontrada sobre rocha ou bainhas velhas de palmeiras, muito comum e aparentemente preferindo planícies costeiras e locais ensolarados. Peralta (2005) relata para área de mata, com hábito rupícola, corticícola ou epixícola. Comum em florestas tropicais e nas árvores de áreas urbanas. Em Caxiuanã apresentou habito terrestre.

Distribuição geográfica: AL, AM, AP BA, ES, FN, GO, MT, PA, PB, PE, PI, PR, RJ, RN, RO, RR, SE e SP. Primeira referência para a área de Caxiuanã.

Material examinado. BRASIL. Pará: Município de Melgaço, FLONA de Caxiuaná, Estação Científica Ferreira Penna, baía de Caxiuaná, várzea ao redor da campina, 4.XI.1996, R. Lisboa, et al. 6111, 6129, 6146 (MG). 
Calymperes pallidum Mitt., Philos. Trans. Royal Soc. London 168: 338. 1879.

Descrição e ilustração: Florschütz (1964); Lisboa (1993) como C. uleanum Broth. e Reese (1993).

Comentários: Filídio com a parte superior fortemente involuta; ápice truncado ou arredondado; cancelinas conspícuas; costa larga, fortemente pluripapilosa, afinando para a base, com ausência de estereídes (Reese, 1993). Pode ser confundida com C. erosum Müll.Hal., porém este apresenta grupos de estereídes na costa e gemas dispostas ao redor da parte superior da costa.

Habitat: Freqüente sobre folhas velhas de palmeiras, em pastos, sendo considerada uma espécie de ocorrência rara (Lisboa, 1993). Na área de estudo foi coletada sobre casca de árvore, tronco de cipó vivo e seco.

Distribuição geográfica: AC, AM, BA, GO, MT, PA e RO. Primeira referência para a área de Caxiuanã.

Material examinado. BRASIL. Pará: Município de Melgaço, FLONA de Caxiuanã, Estação Científica Ferreira Penna, Igarapé Curuá, floresta de terra firme, 18.X.2004, E. Moraes 24, 27 (MG); ibidem, Igarapé Arauá, floresta de terra firme, 25.X.2004, E. Moraes 138 (MG).

Calymperes platyloma Mitt., J. Linn. Soc. Bot. 12: 128. 1869.

Descrição e ilustração: Florschütz (1964) e Reese (1993).

Comentários: Segundo Reese (1993) é considerada uma espécie de rara ocorrência, a maioria tem sido coletada recentemente. Filídio com costa amplamente bordeada com fileiras de células alongadas e margens denteadas são características distintivas. C. smithii Bartram e C. mitrifugax Florschütz se assemelham a esta espécie.

Habitat: Em casca de árvore, tronco em decomposição, florestas tropicais ou savanas.

Distribuição geográfica: AM, AP, BA e PA.

Material examinado. BRASIL. Pará: Município de Melgaço, FLONA de Caxiuanã, Estação Científica Ferreira Penna, Igarapé Grande, Inv. 9, floresta de terra firme, 13.XI.1995, R. Lisboa \& C. Silva 5388 (MG); ibidem, margem do Rio Curuá, mata de várzea, 6.XI.1996, $R$. Lisboa, et al. 6174 (MG); ibidem, Igarapé Arauá, capoeira, 22.X.2004, E. Moraes 109 (MG).

Calymperes rubiginosum (Mitt.) W.D.Reese, Bryologist 78 (1): 92-93. 1975.

Descrição e ilustração: Florschütz (1964) como C. rufum Herz.; Reese (1993) e Lisboa (1993).

Comentários: Segundo Reese (1961), o pequeno tamanho do gametófito a separa das outras espécies de Calymperaceae. Filídios com margens crenuladas; células superiores mamilosas; costa marrom-avermelhada; pequena área ocupada pelas cancelinas; ausência de teníolas. A cor marrom-avermelhada caracteriza facilmente a espécie.

Habitat: Em casca de árvores pequenas, florestas altas de terra firme, em dossel aberto. Tronco de árvore, em floresta plantada no Suriname (Florschütz, 1964). Em Caxiuanã foi coletada também sobre pau podre no chão.

Distribuição geográfica: AM, BA, PA, RO e RR. Primeira referência para a área de Caxiuanã.

Material examinado. BRASIL. Pará: Município de Melgaço, FLONA de Caxiuanã, Estação Científica Ferreira Penna, trilha para torre, floresta de terra firme, 24.IV.1995, R. Lisboa, et al. 4914 (MG); ibidem, Inv. 13, Igarapé Retiro, floresta de terra firme aberta, VI.1996, R. Lisboa 5879 (MG); ibidem, Igarapé Grande, floresta de terra firme, 9.XI.1996, $R$. Lisboa, et al. 6252 (MG).

Syrrhopodon cryptocarpus Dozy \& Molk., Prodr. Fl. Bryol. Surinamensis, 14. 1854.

Descrição e ilustração: Florschütz (1964); Lisboa (1993) e Reese (1993).

Comentários: Gametófitos muito radiculosos, com rizóides marrom-avermelhados; Filídios com margens denteado-serreadas em três fileiras; bases coloridas; cancelinas persistentes com espessamentos transversais; células papilosas e esporófito imerso. A formaçáo dos propágulos ocorrem sobre os filídios velhos (Lisboa, 1993).

Habitat: Geralmente corticícola, em florestas primárias e savanas (Lisboa, 1993). Ocorre sobre paus podres, mas pode ser encontrada sobre cupinzeiros (Reese, 1993).

Distribuição geográfica: AC, AM, MT, PA, RO, RR e SP. Primeira referência para a área de Caxiuaná.

Material examinado. BRASIL. Pará: Município de Melgaço, FLONA de Caxiuanã, Estação Científica Ferreira Penna, Igarapé Grande, Inv. 10, floresta de terra firme, 13.XI.1995, R. Lisboa \& C. Silva 5342 (MG); ibidem, Baía de Caxiuanã, Praia do Lisboa, floresta de terra firme, 29.X.2004, E. Moraes 191, 193 (MG). 1900.

Syrrhopodon cymbifolius Müll.Hal. Hedwigia 39: 262.

Descrição e ilustração: Reese (1981, 1993).

Comentários: Filídios vegetativos oblongo-lingulados, amplamente lanceolados; margens inteiras na borda, serrulada por papilas, estreitamente bordeada abaixo por células hialinas, ou bordeada irregularmente na regiáo dos ombros (as células hialinas algumas vezes sấo intramarginais parecendo com teníolas); as cancelinas finalizando distalmente em ângulo agudo. A forma do filídio se assemelha a $S$. parasiticus (Brid.) Paris. Besch, mas difere pelo tamanho e esporo pequenos, 
filídios geminíferos alargados ou normalmente ausentes e estômatos na base da cápsula.

Habitat: Em florestas, nos ramos de troncos de árvores (Reese, 1984).

Distribuição geográfica: AM, ES, GO, PA e SP. Primeira referência para a área de Caxiuanã.

Material examinado. BRASIL. Pará: Município de Melgaço, FLONA de Caxiuanã, Estação Científica Ferreira Penna, Igarapé Curuazinho, Inv. 11, mata de várzea, 5.XI.1996, A. Ilkiu-Borges, et al. 700 (MG); ibidem, margem do rio Curuá, mata de igapó, 6.XI.1996, R. Lisboa, et al. 6185 (MG); ibidem, Igarapé Grande, floresta de terra firme, 9.XI.1996, R. Lisboa, et al. 6229 (MG).

Syrrhopodon graminicola R.S. Williams, Bulletin of the Torrey Botanical Club 47: 379. pl. 16: f. 14. 1920.

Descrição e ilustração: Florschütz (1964), como $S$. parasiticus (Brid.) Besch. var. disciformis (Müll.Hal.) Florsch., atualmente sinônimo de $S$. africanus subsp. graminicola, segundo Reese (1993, 1995).

Comentários: Filídios com margens onduladas quando secas, as plantas mais velhas, apresentam filídios modificados, formando tufos (rosetas ou coma) partindo do ápice do ramo, denominado de filídios comais. A espécie é similar a S. parasiticus ( $S w$. ex Brid.) Paris, porém diferindo desta, pelas células dos filídios pluripapilosas e bordeadas por células hialinas com margem denteada distalmente.

Habitat: Sobre tronco de árvores pequenas ou gravetos em florestas úmidas (Florschütz, 1964), também sobre cupinzeiros (Reese, 1993). Na área de estudo foi coletada sobre solo.

Distribuição geográfica: AM, ES, PA, SP. Primeira referência para a área de Caxiuanã.

Material examinado. BRASIL. Pará: Município de Melgaço, FLONA de Caxiuanã, Estação Científica Ferreira Penna, baía de Caxiuaná, campina em frente à baia de Caxiuanã, 4.XI.1996, R. Lisbo, et al. 6060 (MG); ibidem, inventário da torre, floresta de terra firme, 07.XI.1996, $A$. Ilkiu-Borges, et al. 836 (MG).

Syrrhopodon hornschuchii Mart., Fl. Brasiliensis 1(2): 6. 1840 .

Descrição e ilustração: Lisboa (1993) e Reese (1993).

Comentários: Filídios planos, menores e largos; cancelinas frágeis, curtas, restritas à base da lâmina; margem da lâmina inferior com dentes expandido-recurvados.

Habitat: Sobre árvores vivas, em mata de terra firme, galhos mortos, pau seco e capoeira (Lisboa,1993). Segundo Reese (1977) tem sido coletada até cerca de 900m de altitude.

Distribuição geográfica: AC, AM, AP, MG, MT, PA, RO, RR e SP.
Material examinado. BRASIL. Pará: Município de Melgaço, FLONA de Caxiuanã, Estação Científica Ferreira Penna, Inv. 13, Igarapé Retiro, floresta de terra firme, 3.XI.1996, A. Ilkiu-Borges, et al. 666 (MG); ibidem, Igarapé Curuá, mata de igapó, 20.X.2004, E. Moraes 50 (MG); ibidem, plot 1 central do TEAM, floresta de terra firme, 21.X.2004, E. Moraes 87 (MG).

Syrrhopodon incompletus Schwägr. var. incompletus. Spec. Musc. Suppl. 2 (1): 119. 1824.

Descrição e ilustração: Lisboa (1993); Reese (1993) e Peralta (2005).

Comentários: Filídios ligulados; ápice agudo; células da lâmina sem papilas; margem multiestratificada na porção mediana e superior, sem borda, células da margem iguais às da lâmina; propágulos restritos ao ápice dos filídios; costa denticulada. Bartram (1949) a reconhece pela base do filídio obovada e clara, com ombros distintos e denteados nos ângulos. Segundo Florschütz (1964) esta espécie é variável, especialmente no formato das células superiores da lâmina. Para Reese (1993) é uma espécie invasora, os filídios são dimórficos, porém indistintos ao microscópio e a base pode apresentar células longas aparentando teníolas.

Habitat: Geralmente abundante por toda a América tropical e subtropical (Reese, 1977). Ocorre sobre toras, troncos de árvores, especialmente palmeiras (Reese, 1993). Em manguezal, mata, restinga e costão rochoso, hábito rupícola e corticícola (Peralta, 2005).

Distribuição geográfica: AC, AM, AP, BA, GO, MG, MS, MT, PA, PE, RO, RJ, RR, PR, SC e SP.

Material examinado. BRASIL. Pará: Município de Melgaço, FLONA de Caxiuanã, Estação Científica Ferreira Penna, Inv. 8, floresta de terra firme, 29.IV.1995, R. Lisboa, et al. 5008, 5051 (MG); ibidem, Inv. 13, Igarapé Retiro, floresta de terra firme, 3.XI.1996, A. Ilkiu-Borges et al. 663 (MG).

Syrrhopodon incompletus Schwägr. var. berteroanus (Brid.) W.D.Reese. Bryologist 80: 9. 1977.

Descrição e ilustração: Reese $(1977,1993)$.

Descrição Detalhada: Plantas da variedade berteroanus são dimórficas com a forma rígida e flexuosa dos filídios. Diferem da var. incompletus principalmente pela forma dos filídios mais estreitos (comumente subulados) e ombros fortemente expandidos, com alguns dentes simples, na lâmina superior. As margens da lâmina superior, às vezes, são uniestratificadas, os esporófitos são como os de S. incompletus Schwägr.

A variedade berteroanus é muito similar a $S$. incompletus var. luridus (Paris \& Broth.) Florsch. diferindo predominantemente pelos dentes simples na margem superior da lâmina. Como na var. luridus, a margem inferior da lâmina é frequentemente pouco bordeada, usualmente linear-subulada a linear- 
lanceolada (ocasionalmente lanceolada) na lâmina superior surgindo abruptamente dos ombros fortemente dilatados. $\mathrm{Na}$ var. luridus, isto é também distintivo. O peristoma pode ser ausente ou presente e rudimentar.

A variabilidade e ampla distribuição da var. berteroanus tem resultado em vários sinônimos. Ela é aparentemente escassa ou ausente mais acima do norte da América do Sul, onde é conhecida somente de poucas coleçóes na Venezuela e uma do Oeste do Peru. A variedade está atribuída para as ilhas Malvinas na base de Dumont d'Urville, coleçáo citada por Bridel (1827).

Habitat: Em troncos de árvores nas florestas de grandes altitudes $(1700 \mathrm{~m})$, em casca de árvore caída e troncos apodrecidos (Reese, 1993 e 1977). Em Caxiuanã foi coletada uma única vez, no solo argiloso, sobre árvore de Tetragrastis panamensis.

Distribuição geográfica: AP, MG, PR, RJ, SC e SP. Esta variedade é referida como nova ocorrência para o Estado do Pará.

Material examinado. BRASIL. Pará: Município de Melgaço, FLONA de Caxiuanã, Estação Científica Ferreira Penna, Inv. 7, floresta de terra firme, X.1994, R. Lisboa, et al. 3668 (MG).

Syrrhopodon incompletus var. luridus (Paris \& Broth.) Florsch. Mosses of Suriname 1: 163. 1964.

Descrição e ilustração: Reese (1977, 1993).

Comentários: A variedade luridus é semelhante à variedade berteroanus, porém difere principalmente pelos dentes emparelhados na margem superior da lâmina, com presença ocasional de células alongadas formando uma borda irregular na margem inferior, é aproximadamente uniforme na base parecendo teníolas e ombros fortemente dilatados.

Habitat: Em casca de árvore nas florestas formando tufos densos ou frouxos (Reese, 1977).

Distribuição geográfica: AC, AM, PA e RR. Primeira referência da variedade para Caxiuaná.

Material examinado. BRASIL. Pará: Município de Melgaço, FLONA de Caxiuanã, Estação Científica Ferreira Penna, Inv. 13, Igarapé Retiro, floresta de terra firme, 24.IV.1996, R. Lisboa 5883 (MG); ibidem, no igapó do Curuá, mata de igapó, 20.X.2004, E. Moraes 80 (MG); ibidem, floresta de terra firme, 1.X.2004, E. Moraes 81 (MG).

Syrrhopodon ligulatus Mont., Syll. Gen. Spec. Crypt. 47. 1856.

Descrição e ilustração: Florschütz (1964); Lisboa (1993) e Peralta (2005).

Comentários: Espécie pequena $(2,5-5,0 \mathrm{~mm})$, crispada quando seca; filídios ligulados; ápice abruptamente obtuso; margem completamente bordeada por células longas e hialinas alcançando até a metade (Reese, 1993). De acordo com Florschütz (1964) esta margem é variável, podendo chegar ao meio da lâmina ou estar inteiramente ausentes. À primeira vista as plantas pequenas de Syrrhopodon gaudichaudii Mont. podem se assemelhar a $S$. ligulatus, porém, se diferencia entre outras características, pelos filídios completamente bordeados por células hialinas e um dente forte na ponta do filídio.

Habitat: Sobre troncos de árvores (Florschütz, 1964). Em baixas altitudes (Bartram, 1949). Troncos apodrecidos, raramente sobre pedras, também sobre cupinzeiro em vegetaçôes de florestas úmidas ou esclerófilas (Lisboa, 1993). Foi coletada na área sobre cipó.

Distribuição geográfica: AM, AP, BA, DF, GO, MG, MS, MT, PA, PE, RJ, RO, RR e SP. Primeira referência para $\mathrm{a}$ área de Caxiuaná.

Material examinado. BRASIL. Pará: Município de Melgaço, FLONA de Caxiuanã, Estação Científica Ferreira Penna, Igarapé Grande, Inv. 9, floresta de terra firme, 13.XI.1995, R. Lisboa \& C. Silva 5376 (MG); ibidem, margem do Rio Curuá, mata de igapó, 6.XI.1996, R. Lisboa, et al. 6171 (MG); ibidem, Igarapé Curuazinho, margem esquerda, mata de várzea, 27.X.2004, E. Moraes 151 (MG).

Syrrhopodon parasiticus (Sw. ex Brid.) Paris., Ann. Sci. Nat. Bot. sér. 8 (1): 298. 1985.

Descrição e ilustração: Florschütz (1964); Lisboa (1993) e Peralta (2005).

Comentários: Filídios dimórficos, com células lisas ou unipapilosas, gemas filamentosas e freqüentemente com borda incompleta de células longas e hialinas. Ápice agudo; margem inteira, bordeada por células lineares, exceto no ápice; propágulos surgindo em toda a extensão ventral da costa sem papila. Ápice das cancelinas agudo. A espécie $S$. graminicola é similar, porém tem células pluripapilosas e uma borda completa, denteada distalmente.

Habitat: Corticícola, epixícola, rupícola, em área de mata e restinga (Peralta, 2005). Sobre folhas de plantas superiores, florestas úmidas e igapós, até $1.600 \mathrm{~m}$ de alt. (Reese, 1978).

Distribuição geográfica: AC, AM, BA, ES GO, MG, MS, MT, PA, PE, PR, RJ, PR, RO, RR, SC e SP. Primeira referência para a área de Caxiuaná.

Material examinado. BRASIL. Pará: Município de Melgaço, FLONA de Caxiuanã, Estação Científica Ferreira Penna, Igarapé Curuazinho, Inv. 11, capoeira (40 anos), 5.XI.1996, A. Ilkiu-Borges, et al. 741 (MG).

Syrrhopodon prolifer Schwägr., Spec. Musc. Frond. Suppl. 2 (2): 99. 1827.

Descrição e ilustração: Florschütz (1964); Lisboa (1993) e Peralta (2005). 
Comentários: Filídio com porçáa superior fortemente linear; ápice agudo; borda da margem conspícua chegando ao ápice; células pluripapilosas; base fortemente adpressa sem cílios. Reese (1993) evidencia as características da espécie pelas células pequenas e obscuras, densamente papilosas; filídios lineares e pequenos.

Habitat: Corticícola e epixícola, em área de mata e restinga (Peralta, 2005). Matas de terra firme e matas com nevoeiros (Lisboa, 1993). Sobre rochas (Bartram, 1949) e pedras.

Distribuição geográfica: AL, AM, BA, DF, ES, GO, MG, MT, PA, PE, PI, PR, RJ, RO, RS, SC, SE e SP. Primeira referência para a área de Caxiuaná.

Material examinado. BRASIL. Pará: Município de Melgaço, FLONA de Caxiuanã, Estação Científica Ferreira Penna, Inv. do Heliponto, capoeira, 4.V.1995, J. Melo 226 (MG); ibidem, fora do inventário da torre, floresta de terra firme, 7.XI.1996, A. Ilkiu-Borges, et al. 844 (MG).

Syrrhopodon rigidus Hook. \& Grev., Edinburgh J. Sci. 3: 226.1825.

Descrição e ilustração: Florschütz (1964) e Reese (1977, 1993).

Comentários: Gametófitos verde-escuros; células medianas engrossadas; filídios altamente dimórficos, circulares a retangulares; margem da lâmina superior duplamente denteada, simples e denteada na regiáo dos ombros até a base do filídio, com dentes expandido-recurvados; cancelinas persistentes, coloridas.

Habitat: Em troncos vivos, lianas, raízes, solos e rochas em ambientes úmidos de florestas, próximo ao nível do mar, acima de $2.100 \mathrm{~m}$, mais frequentemente acima de $300 \mathrm{~m}$ (Reese, 1993). Em Caxiuaná foi coletada uma única vez sobre caule de árvore viva.

Distribuição geográfica: AM, AP, MG, MS, PA RJ, RO, RR e SP.

Material examinado. BRASIL. Pará: Município de Melgaço, FLONA de Caxiuanâ, Estaçâo Científica Ferreira Penna, baía de Caxiuaná, picada entre os rios Curuá e Puraquequara, floresta de terra firme, 14.I.1993, R. Lisboa 2279 (MG). 1946.

Syrrhopodon simmondsii Steere, Bryologist 49: 8.

Descrição e ilustração: Lisboa (1993) e Reese (1978, 1993).

Comentários: filídios pequenos, levemente curvados ou eretos; presença de cílios conspícuos e delicados na margem; cancelinas estreitas; células variáveis; propágulos escassos ao longo da costa.

Habitat: Apesar de não ser comum, pode ser encontrada em abundância sobre solo arenoso, húmus, tronco apodrecido, sobre árvores e em altitudes até 600m. (Reese, 1993). Florestas de terra firme e de galeria, campinas de areia branca e savanas (Reese, 1978).

Distribuição geográfica: AM, PA, RO. Primeira referência para Caxiuanã.

Material examinado. BRASIL. Pará: Município de Melgaço, FLONA de Caxiuaná, Estação Científica Ferreira Penna, Inv. 6, floresta de terra firme, X. 1994, R. Lisboa, et al. 3307 (MG); ibidem, Igarapé Grande, Inv. 9, floresta de terra firme, 13.XI.1995, R. Lisboa \& C. Silva 5324, 5394 (MG).

Syrrhopodon xanthophyllus Mitt., Jour. Linn. Soc. Bot. 12: 115. 1986.

Descrição e ilustração: Lisboa (1993) e Reese (1977, 1993).

Comentários: Diagnosticada pela cor amarelada na parte superior e marrom-avermelhada abaixo; filídio com ápice geralmente mucronado; cancelinas extremamente reduzidas, frágeis e esporófitos imersos. Difere de $S$. cryptocarpos Dozy \& Molk, que também possui esporófito imerso, pela base do filídio marrom-avermelhado, ausência de perístoma e cancelinas efêmeras (Lisboa, 1993).

Habitat: Corticícola, porém já coletado sobre pedras ao longo de corredeiras, sobre ninho de cupins e solo depois de queimada, mata de terra firme e principalmente em cerrado (Lisboa, 1993). Em Caxiuanã foi coletada uma única vez sobre árvore viva.

Distribuição geográfica: AM, PA e RO. Primeira referência para a área de Caxiuaná.

Material examinado. BRASIL. Pará: Município de Melgaço, FLONA de Caxiuanã, Estação Científica Ferreira Penna, inventário 9, Igarapé Grande, floresta de terra firme, 13.XI.1995, R. Lisboa \& C. Silva 5325 (MG).

\section{FISSIDENTACEAE Schimp.}

Fissidens elegans Brid., Musc. Rec. Supp. 1: 167. 1806.

Descrição e ilustração: Pursell (1984) e Lisboa (1993).

Comentários: Apresenta caulídio com 03-10 pares de filídios, os superiores mais ou menos falciformes; costa subpercurrente; células da lâmina vaginante pluripapilosas, bordeadas por células hialinas e longas, usualmente na parte basal ou alcançando metade da lâmina. Pode ser confundida com F. intramarginatus Müll Hal. Contudo esta se distingue por uma limbídia mais forte que se apresenta consistentemente nas lâminas vaginantes de todas as folhas maduras.

Habitat: Espécie muito comum em solos, casca de árvores, tronco caído e cupinzeiros, podendo ocorrer também sobre rochas (como matacão e pedra calcária) (Lisboa, 1993).

Distribuição geográfica: AC, AM, ES, FN, GO, MG, MS, MT, PA, PE, RJ, RO, RR, SC e SP. 
Material examinado. BRASIL. Pará: Município de Melgaço, FLONA de Caxiuanã, Estação Científica Ferreira Penna, Igarapé Grande, inventário 9, floresta de terra firme, sobre árvore viva de no 37, 13.XI.1995, E. Moraes 5308 (MG); ibidem, inventário 6, mata de terra firme com concressóes rochosas, sobre árvore de Ocotea sp. X.1994, R. Lisboa, C. Rosário \& R. Babia 3557 (MG); ibidem, inventário 7, mata de terra firme com concressóes rochosas, sobre árvore de Machira sclerofila. X.1994, R. Lisboa, C. Rosário \& R. Bahia 3801 (MG).

Fissidens guianensis Mont., Ann. Sci. Nat. Bot. sér. 2 (14): 340. 1840.

Descrição e ilustração: Florschütz (1964); Lisboa (1993) e Peralta (2005).

Comentários: Espécie muito variável, inclusive no mesmo espécime. Ápice obtuso, agudo ou acuminado; lâmina vaginante até $2 / 3$ do comprimento total do filídio com bordo marginal ou intramarginal; costa percurrente ou terminando poucas células abaixo do ápice; células marginais com uma ou duas papilas. O único caráter constante e confiável que a separa de outras espécies como F. garberi Lesq \& James, são as células achatadas ou menos salientes, finamente papilosas da lâmina vaginante (Florschutz,1964).

Habitat: Encontrada sobre base de árvores, troncos em decomposiçáo, pedras e solos argilosos ou arenosos; mata de terra firme e mancha de cerrado (savanas) (Lisboa, 1993).

Distribuição geográfica: AC, AM, ES, GO, MS, MT, PA, PE, PI, RJ, RO, RR, SC, SP e TO.

Material examinado. BRASIL. Pará: Município de Melgaço, FLONA de Caxiuanã, Estação Científica Ferreira Penna, inventário 13, Igarapé Retiro, floresta de terra firme, sobre árvore de Lecytidaceae, 3.XI.1996, A. Ilkiu-Borges, $R$. Lisboa e M. Silva 670 (MG); ibidem, Igarapé Curuá, mata de igapó, sobre tronco de árvore viva atravessando o igarapé, 20.X.2004, E. Moraes 50 (MG); ibidem, Igarapé Arauá, no solo do igapó que corta a trilha, mata de igapó, sobre tronco em decomposição em contato com a água, 25.X.2004, E. Moraes 136 (MG).

Fissidens pauperculus M.Howe, Erythea 2: 97. 1. 1894.

Descrição e ilustração: Florschütz (1964).

Descrição detalhada: A espécie é muito pequena, verdeamarronzada, gametófitos crescendo dispersos ou próximos, ramos com $2 \mathrm{~mm}$ comp. com 4-5 pares de filídios, pequenos abaixo, aumentando na parte superior do ramo, ápice dos filídios oblongo-lanceolados, às vezes espatulados, retusos, na junção do ápice e lâmina vaginante, agudo ou ligeiramente acuminado, margens finamente crenuladas, projetando células na parte superior ( $1,5 \mathrm{~mm}$ de comp. e $0,5 \mathrm{~mm}$ largura). Lâmina vaginante alcançando 1/3-1/2 do comprimento total do filídio, frequentemente desigual e curvada em direção à costa, finamente serreada para o ápice, costa forte e mais ou menos flexuosa, e frequentemente curvada na junção da lâmina vaginante e lâmina apical, finalizando bem abaixo do ápice. Células da lâmina apical largas, pelúcidas, hexagonais ou alongado-hexagonal a retangulares, especialmente ao longo da costa, $30 \mu(-40)$ comp., $15 \mu$ largura, pequenas em direção à margem $(9-12 \mu)$. Na variedade surinamense, são pequenas, com uma ou duas fileiras na margem, formando uma borda inconspícua; na base da lâmina vaginante, poucas fileiras de células alongadas, plantas masculinas pequenas com apenas 2 pares de filídios, os perigoniais aproximadamente orbiculares na lâmina vaginante. Seta variando em $3-5 \mathrm{~mm}$ de comprimento, cápsula ovóide, curvada, $0,75 \mathrm{~mm}$ de comprimento e $0,3 \mathrm{~mm}$ de largura, perístoma denteado normalmente com forquilha grossamente espiralada, com a tampa cônico-rostrada. Caliptra cuculada.

Habitat: Encontrada em ambientes úmidos, argilosos, florestas tropicais densas. Em Caxiuanã foi coletada sobre árvore de Tinteira e cupinzeiro de árvore (Florschütz, 1964).

Distribuição geográfica: PE. Primeira ocorrência para o Estado do Pará e Amazônia Brasileira.

Material examinado. BRASIL. Pará: Município de Melgaço, FLONA de Caxiuanã, Estação Científica Ferreira Penna, Igarapé Curuazinho, inventário 11, capoeira, sobre árvore de Tinteira, 5.XI.1996, A. Ilkiu-Borges, R. Lisboa \& $M$. Silva 748 (MG); ibidem, Furo do Camuim, mata de várzea, sobre cupinzeiro alojado em tronco de árvore, 28.XI.2000, R. Lisboa \& A. Ilkiu-Borges 6949 (MG).

Fissidens pellucidus Hornsch. Linnaea 15: 146. 1841.

Descrição e ilustração: Crum \& Anderson (1981), Lisboa (1993) como Fissidens prionodes Mont. f. hornschuchii (Mont.) Florsch e F. prionodes Mont. f. puiggarii (Geheeb \& Hampe) Florsch. atualmente sinônimos de F. pellucidus var. pellucidus, segundo o autor acima e Churchill (1998) e Yano \& Oliveirae-Silva (1997).

Comentários: Caracteriza-se pela coloração avermelhada, gametófitos moderadamente grandes; paredes celulares espessas e pelúcidas, unipapilosas. Há formas de transição na espécie que dificultam a identificaçáo, pois as paredes celulares são menos espessas, filídios mais largos e papilas sobre o lúmen das células não muito distintas (Florschütz, 1964).

Habitat: Em solos ou pedras, casca de árvores, troncos apodrecidos e cupinzeiros, raízes de palmeiras, florestas úmidas, savanas, mata alta de terra firme e capoeiras (Lisboa, 1993).

Distribuição geográfica: AM, MG, MT, PA, PR, RJ, RO, RR, RS, SC e SP. Primeira referência para a área de Caxiuaná. 
Material examinado. BRASIL. Pará: Município de Melgaço, FLONA de Caxiuanã, Estação Científica Ferreira Penna, Igarapé Arauá, plot 4 do TEAM, mata de igapó, na beira do igarapé no solo, 22.X.2004, E. Moraes 119 (MG); ibidem, fora do plot 4, mata de igapó, sobre raiz morta na linha da água, 25.X.2004, E. Moraes 126 (MG); ibidem, plot 4 central do TEAM, próx a árvore de no 94 , floresta de terra firme, sobre barro, 25.X.2004, E. Moraes 129 (MG).

Fissidens prionodes Mont., Ann. Sci. Nat. 2 (3): 200. 1835.

Descrição e ilustração: Florschütz (1964) e Lisboa (1993) como Fissidens prionodes Mont. fo. Prionodes.

Comentários: Distingue-se pela disposição equitante dos filídios, assemelhando-se a um leque, coloração avermelhada a marrom-escura; filídios linear-lanceolados com costa excurrente formando um forte apículo.

Habitat: Encontrada sobre barro e em mata de terra firme (Lisboa, 1993).

Distribuição geográfica: AC, AM, BA, GO, MG, PA, PB, PE, PI, RJ, RO, RR e SP.

Material examinado: BRASIL. Pará: Município de Melgaço, FLONA de Caxiuaná, Igarapé Curuá, plot 1 do TEAM, floresta de terra firme, sobre cupinzeiro no solo, na entrada do igarapé, 18.X.2004, E. Moraes 23 (MG); Ibidem, plot 1 central do TEAM, próximo a árvore de $\mathrm{n}^{\circ} 244$, sobre resto de raiz em decomposição, 21.X.2004, E. Moraes 88 (MG); ibidem, Igarapé Arauá, plot 4 do TEAM, capoeira de 30 anos, na trilha, sobre raiz apodrecida no solo, 22.X.2004, E. Moraes 107 (MG).

Fissidens submarginatus Bruch., Flora 29: 133. 1846.

Comentários: Caracteriza-se pela margem da lâmina vaginante fortemente bordeada por células longas e estreitas, alcançando ou ultrapassando a junção com a lâmina apical, células unipapilosas. Pode ser confundida com $F$ e elegans, porém Griffin III (1979) as difere justamente pela borda marginal, alcançando o cume da lâmina vaginada, células dos filídios distintas, unipapilosas com paredes delgadas.

Descrição e ilustração: Pursell (1997) e Peralta (2005).

Habitat: Pode ser encontrada em ninhos de cupins, restos de madeira, sobre barro, pedras calcáreas em locais úmidos e sombreados, mata de terra firme e mancha de cerrado (Lisboa, 1993). Em Caxiuanã foi coletada uma única vez sobre árvore viva.

Distribuição geográfica: AC, AM, BA, FN, GO, MG, MT, MS, PA, PE, PI, RJ, RO, SC, SP e TO. Primeira referência para a área de Caxiuaná.

Material examinado. BRASIL. Pará: Município de Melgaço, FLONA de Caxiuanâ, Estaçấo Científica Ferreira
Penna, inventário 8, ao lado da torre, floresta de terra firme, sobre árvore viva, 29.IV.1995, R. Lisboa, et al., 5027 (MG).

\section{HYPNACEAE Schimp.}

Chryso-hypnum diminutivum (Hampe) W.R.Buck, Brittonia 36: 182. 1984.

Descrição e ilustração: Sharp et al., (1994) e Florschütz-De Waard \& Veling (1996).

Comentários: Filídio apresentando células com papilas nas extremidades superior e inferior, células alares quadráticas a retangulares. Pode ser facilmente distinguida de Mittenothamnium reptans (Hedw.) Cardot., pelos filídios do ramo ovalados a ovalado-lanceolados, pseudoparafilia filamentosa a fortemente lanceolada.

Habitat: Em casca e troncos de árvores, solo. Preferencialmente áreas de cultivo, florestas baixas de savana, às vezes em florestas de planície (Florschütz-de-Waard \& Veling, 1996).

Distribuição geográfica: AC, AM, AP, ES, DF, GO, MG, MS, MT, PA, PE, PR, RJ, RR, RS, SC e SP. Primeira referência para a área de Caxiuaná.

Material examinado. BRASIL. Pará: Município de Melgaço, FLONA de Caxiuanã, Estação Científica Ferreira Penna, inventário 13, Igarapé Retiro, floresta de terra firme, sobre árvore viva de no 3, 24.IV.1996, R. Lisboa 5817 (MG); ibidem, Baía de Caxiuanã, várzea ao redor da campina, sobre árvore de Pracaxi, 4.XI.1996, R. Lisboa, A. Ilkiu-Borges \& M. Silva 6111 (MG); ibidem, sobre Cajarana, 4.XI.1996, $R$. Lisboa, A. Ilkiu-Borges \& M. Silva 6135 (MG).

Ectropothecium leptochaeton (Schwägr.) W.R.Buck, Brittonia 35: 311. 1983.

Descrição e ilustração: Sharp et al., (1994) e Florschütz-De Waard \& Veling (1996).

Comentários: Filídios fortementes falcados, homômalos. Filídios periqueciais lanceolados, gradualmente longoacuminados, subinteiros a serrulados na parte superior.

Habitat: Pode ser encontrada sobre troncos de árvores e madeira em decomposição. Ocasionalmente sobre pedras (Florschütz-De Waard \& Veling, 1996).

Distribuição geográfica: AM, ES, MG, MS, MT, PA, PR, RJ e SC.

Material examinado. BRASIL. Pará: Município de Melgaço, FLONA de Caxiuanã, Estação Científica Ferreira Penna, baía de Caxiuanã, mata entre os igarapés Tijucaquara e Arauá, floresta de terra firme, sobre tronco de árvore viva, 18.I.1993, R. Lisboa 2330 (MG); ibidem, Rio Arauá, sítio abandonado, floresta de terra firme, sobre raízes expostas, 5.V.1995, R. Lisboa, et al., 5258 (MG); ibidem, Igarapé Curuá, 
vegetação de igapó, sobre tronco de árvore viva, 20.X.2004, E. Moraes 48 (MG).

Isopterygium subbrevisetum (Hampe) Broth., Nat. Pfl. Fam. 1 (3): 1081. 1908.

Descriçấo e ilustração: Ireland (1992); Sharp et al. (1994) e Florschütz-De Waard \& Veling (1996).

Comentários: Diferencia-se de Isopterygium tenerum ( $\mathrm{Sw}$.) Mitt. principalmente pelo hábito dos ramos ascendentes, estreitos e eretos, cápsula ereta ou ligeiramente inclinada na maturidade, filídios simétricos, células alares usualmente subquadráticas.

Habitat: É encontrada sobre casca de árvores, tronco podre, normalmente em áreas abertas no meio de florestas úmidas (Florschütz-De Waard \& Veling, 1996).

Distribuição geográfica: AM, BA, MG, PA, RJ, SC e SP. Primeira referência para a área de Caxiuanã.

Material examinado. BRASIL. Pará: Município de Melgaço, FLONA de Caxiuanã, Estação Científica Ferreira Penna, Igarapé Arauá, plot 4 TEAM, capoeira, sobre solo, 22.X.2004, E. Moraes 100 (MG); ibidem, Igarapé Laranjal, vegetação de várzea, sobre raiz de árvore viva em contato com a água, 28.X.2004, E. Moraes 164 (MG); ibidem, sobre tronco em decomposição submerso na água, 28.X.2004, $E$. Moraes 166 (MG).

Isopterygium tenerum (Sw.) Mitt., J. Linn. Soc. Bot. 12: 499.1869.

Descrição e ilustração: Ireland (1992); Sharp et al. (1994) e Florschütz-De Waard \& Veling (1996).

Comentários: Espécie mais comum e variável do gênero. É diferenciada pelos filídios aplainados, ovalado-lanceolados, assimétricos, células alares em pequenos agrupamentos e a ocorrência de gemas filamentosas nos caulídios. (Sharp et al. 1994).

Habitat: Sobre troncos de árvores vivas, em decomposição, ocasionalmente epifilos e terrestre em lugares úmidos. Ocorre em todos os tipos de vegetação, preferencialmente em habitats úmidos bem iluminados, como em áreas molhadas em vegetação de savana e próximos a riachos, (Florschütz-deWaard \& Veling, 1996). Raramente em rochas.

Distribuição geográfica: AC, AM, BA, DF, ES, GO, MG, MS, MT, PA, PB, PE, PI, RO, PR, RJ, RR, RS, SC e SP.

Material examinado. BRASIL. Pará: Município de Melgaço, FLONA de Caxiuanã, Estação Científica Ferreira Penna, Igarapé Laranjal, vegetaçáo de várzea, sobre raiz de árvore viva em contato com a água, 28.X.2004, E. Moraes 164 (MG); ibidem, sobre tronco em decomposição atravessando no meio do igarapé, 28.X.2004, E. Moraes 177 (MG); ibidem, Baía de Caxiuaná, campina arenosa, sobre tronco em decomposição, 29.X.2004, E. Moraes 184 (MG).
Vesicularia vesicularis (Schwägr.) Broth., Nat. Pfl. Fam. 1(3): 1094. 1908.

Descrição e ilustração: Sharp et al., (1994) e Florschütz-De Waard \& Veling (1996).

Comentários: Filídios largamente ovalados, curto acuminados, falcados, laxos, com células oblongo-hexagonais; ápice apiculado; margem inteira; base truncada; costa dupla e curta. Assemelha à primeira vista a Leucomium strumosum pela forma dos filídios e areolação. Porém, difere pelas células mais curtas e forma de crescimento fortemente complanada.

Habitat: Cresce sobre solo, húmus, madeira em decomposição, rochas e na base dos troncos das árvores (Churchill \& Linares, 1995). Tem preferência por habitats úmidos e escuros. Distribuição geográfica: AC, AM, BA, ES, MG, MS, MT, PA, PE, PI, PR, RJ, RO, RR, RS, SC e SP.

Material examinado. BRASIL. Pará: Município de Melgaço, FLONA de Caxiuanã, Estação Científica Ferreira Penna, Igarapé Curuá, floresta de terra firme, sobre tronco em decomposição, 18.X.2004, E. Moraes 29 (MG); ibidem, no igapó da Cida, que atravessa a trilha do Plot 1 , vegetação de igapó, sobre tronco em decomposição, 21.X.2004, E. Moraes 98 (MG); ibidem, Igarapé Arauá, plot 4 TEAM, floresta de terra firme, sobre tronco em decomposição em clareira, 22.X.2004, E. Moraes 110 (MG).

\section{LEUCOBRYACEAE Schimp.}

Leucobryum albidum (Brid. ex P.Beauv.) Lindb., Öefvers. Förh. Kongl. Svenska Vetensk. AKad. 20: 403. 1863.

Descrição e ilustração: Yano (1992) e Peralta (2005).

Comentários: Caracteriza-se pelo hábito pequeno; ápice obtuso e apiculado e a base dos filídios em corte trasversal com 4 camadas irregulares de células leucocísticas.

Habitat: Cresce principalmente sobre troncos de árvores vivas em matas bem iluminadas como campina e cerrado, porem encontra-se em todos os locais desde a beira-mar até o interior de matas escuras, tendo preferência por várias espécies de palmeiras (Yano, 1992).

Distribuição geográfica: BA, GO, MT, PA, PR, RJ, RO, RS, SC, SP e TO. Primeira referência para a área de Caxiuanã.

Material examinado. BRASIL. Pará: Município de Melgaço, FLONA de Caxiuanã, Estação Científica Ferreira Penna, inventário 8 , floresta de terra firme, sobre tronco caído no chão, 30.IV.1995, J. Melo, 158 (MG); ibidem, inventário 6, mata de terra firme com concressōes rochosas, sobre árvore viva, X.1994, R. Lisboa, C. Rosário \& R. Bahia 3590 (MG); ibidem, inventário 7, mata de terra firme solo argiloso, sobre árvore de Tetragastris panamensis (Engl.) Kuntze (Breu), X.1994, R. Lisboa, R. Bahia e C. Silva 3861 (MG). 
Leucobryum crispum Müll.Hal. Syn. Musc. 1: 78. 1848 .

Descrição e ilustração: Yano (1992) e Peralta (2005).

Comentários: Gametófitos verde-esbranquiçados, irregularmente ramificados, em densos tapetes. Filídios patentes, crispados ou flexuosos, às vezes pouco falcados, 5-9 (-10) $\mathrm{mm}$ de comp. 0,5-0,7 $\mathrm{mm}$ de largura, ápice subtubuloso, irregularmente denteado. Vista superficial do filídio: células do ápice estreito-retangulares, as medianas retangulares, da base longo-retangulares. Corte transversal da costa: ápice e região mediana 2 (1 e 1), base-central 2 ( 1 e 1 ), mais para margem 4 (2 e 2) camadas de leucocistos. Clorocistos mais próximos à superfície ventral do filídio. Lâminas côncavas com 5-6 (-8) fileiras de células leucocísticas.

Habitat: Cresce principalmente no solo (humoso, terroso ou arenoso) de matas primárias e secundárias, às vezes ocorre na base de troncos em decomposição e em rochas no solo de florestas ou próximos a cachoeira, raramente nas bases de árvores vivas (Yano, 1992).

Distribuição geográfica: AM, AP, BA, DF, ES, GO, MG, MT, PR, RJ, RO, RR, RS, SC e SP. Referida como nova ocorrência para o Estado do Pará.

Material examinado. BRASIL. Pará: Município de Melgaço, FLONA de Caxiuanã, Estação Científica Ferreira Penna, baía de Caxiuanã, Estação ecológica de Caxiuaná, picada entre os rios Curuá e Puraquequara, floresta de terra firme, sobre tronco caído e apodrecido, 14.01.1993, R. Lisboa 2284 (MG); ibidem, mata próxima à estação, floresta de terra firme, sobre pau podre caído, 9.X.1993, R. Lisboa, R. Babia \& M. Silva 2485 (MG); ibidem, Igarapé Retiro, inventário 13, floresta de terra firme, sobre árvore viva de no 42, 03.XI.1996, A. Ilkiu-Borges 664 (MG).

Leucobryum martianum (Hornsch.) Hampe, Linnaea 17: 317. 1843.

Descrição e ilustração: Costa (1988) e Yano (1992).

Comentários: A espécie caracteriza-se por filídios falcados unilateralmente, às vezes eretos, outras crispados, ápice apiculado a agudo; no corte transversal os clorocistos estáo mais perto da superfície ventral do filídio; leucocistos dorsais são convexos ao longo de todo filídio; há uma célula diferenciada entre as células leucocísticas do vértice do mesmo.

Habitat: Troncos apodrecidos, vivos ou mortos; solo arenoso, pedras úmidas próximo de quedas d'água; pouco comum em regiôes costeiras. É abundante na região amazônica formando imensos tapetes sobre o húmus nas florestas de terra firme (Yano, 1992).

Distribuição geográfica: AC, AM, AP, BA, DF, ES, CE, MA, MG, MT, PA, PE, PR, RJ, RO, RR, RS, SC, SE, SP e TO.
Material examinado. BRASIL. Pará: Município de Melgaço, FLONA de Caxiuanã, Estação Científica Ferreira Penna, Igarapé Curuá, na entrada do plot 1 de 100ha, floresta de terra firme, sobre tronco em decomposição, 18.X.2004, E. Moraes 31 (MG); ibidem, próximo ao piquete 04/00 dentro da trilha, mata de igapó, sobre raiz de árvore viva, 20.X.2004, E. Moraes 70 (MG); ibidem, Igarapé Arauá, plot 4 do TEAM, mata de igapó, sobre raízes escoras, 22.X.2004, E. Moraes $116(\mathrm{MG})$.

Ochrobryum gardneri (Müll.Hal.) Lindb. Journal of the Linnean Society, Botany 12: 108. 1869.

Descrição e ilustração: Yano (1992).

Comentários: Caracteriza-se pelos tufos de gemas globosas ou piriformes no ápice do filídio. Quando fértil é facil reconhecê-la pela cápsula hemisférica, caliptra cônica com rostro muito longo e franjada na base.

Habitat: Troncos vivos ou mortos (exceto na base), com ou sem casca, raramente sobre rochas úmidas, no interior de matas claras (cerrados) e semi-úmidas a um tanto secas (Yano, 1992).

Distribuição geográfica: AM, BA, DF, CE, GO, MG, MS, MT, PA, PE, RJ, RO, SP e TO. Primeira referência para $\mathrm{a}$ área de Caxiuaná.

Material examinado. BRASIL. Pará: Município de Melgaço, FLONA de Caxiuanã, Estação Científica Ferreira Penna, Rio Curuá, inventário 11, floresta de terra firme, sobre árvore de Acapú, 5.XI.1996, A. Ilkiu-Borges, R. Lisboa \& M. Silva 791 (MG); ibidem, inventário da torre, floresta de terra firme, sobre árvore caída, 5.XI.1996, A. Ilkiu-Borges, R. Lisboa \& M. Silva 834 (MG), ibidem, Igarapé Grande, inventário 10 , floresta de terra firme, sobre árvore viva de ${ }^{\circ}$ 252, 14.VI.1995, R. Lisboa 5487 (MG).

Octoblepharum albidum Hedw. var. albidum Spec. Musc. 50. 1801.

Descrição e ilustração: Costa (1988); Yano (1992) e Peralta (2005).

Comentários: filídio com ápice denticulado, acuminado, raramente agudo, patente, pouco recurvado; aletas ovaladas a oblongas. Quando fértil, a cápsula é ovóide com seta curta. Pode ser confundida com O. cylindricum, Schimp. ex Mont. a qual se distingue por ter setas com mais de $10 \mathrm{~mm}$ de largura, cápsulas cilíndricas, dentes do perístoma fortemente trabeculados e ápices dos filídios inteiros.

Habitat: Troncos de árvores vivas ou em decomposição, sobre pedras, solo arenoso, rochas, geralmente graníticas, lugares secos ou úmidos. Na regiáo amazônica é abundante sobre troncos de palmeiras e nos vasos e placas de xaxim com orquídeas. (Yano, 1992). Os filídios de O. albidum var. albidum apresentam sua capacidade regenerativa a temperatura 
ambiente por 29 semanas. É uma espécie muito freqüente na área (Egunyomi, 1979).

Distribuição geográfica: AC, AL, AM, AP, BA, CE, DF, ES, FN, GO, MA, MG, MS, MT, PA, PB, PE, PI, PR, RJ, RN, RO, RR, RS, SC, SE, SP e TO.

Material examinado. BRASIL. Pará: Município de Melgaço, FLONA de Caxiuanã, Estação Científica Ferreira Penna, Furo do Camuim, inventário em área de manejo de Palmito, mata de várzea, sobre tronco de árvore viva, 24.XI.2000, R. Lisboa, et al., 6878 (MG); ibidem, Igarapé Curuá, na trilha depois do piquete $04 / 00$, mata de igapó, sobre raiz árvore viva no solo, 20.X.2004, E. Moraes 70 (MG); ibidem, Igarapé Arauá, plot 4 do TEAM, capoeira, sobre raiz de Palmeira, 22.X.2004, E. Moraes 101 (MG).

Octoblepharum albidum Hedw. var. violascens Müll. Hal., Linnaea 19: 208. 1846.

Comentários: De acordo com Yano (1992) a variedade violascens Müll.Hal. difere da variedade albidum Hedw. pelos filídios mais largos, delicados e com manchas purpúreas ou violáceas na base, margem das aletas com pequenos dentículos.

Descrição e ilustração: Yano (1992).

Habitat: Cresce em casca de árvore apodrecida, sobre palmeiras e rochas Yano (1982). Distribuição geográfica: AC, AM, BA, MT, MS, PA, RJ, RO, RR, SE e SP.

Material examinado. BRASIL. Pará: Município de Melgaço, FLONA de Caxiuanã, Estação Científica Ferreira Penna, Igarapé Curuazinho, entrada do plot 6 do TEAM, mata de várzea, sobre tronco de árvore viva, 26.X.2004, E. Moraes 148 (MG); ibidem, margem esquerda, mata de várzea, sobre tronco de árvore viva, 26.X.2004, E. Moraes 151 (MG); ibidem, Rio Curuá, Heliponto, capoeira, sobre tronco de árvore viva ao nível do solo, 27.X.2004, E. Moraes 159 (MG).

Octoblepharum cocuiense Mitt. J. Linn. Soc. Bot. 12: 109. 1869.

Descrição e ilustração: Costa (1988) e Yano (1992). Atualmente sinônimo de Octoblepharum pellucidum Müll. Hal., de acordo com Churchill (1998). Esta espécie foi referida para a área de estudo em trabalhos anteriores, como Octoblepharum pellucidum.

Comentários: Os espécimes são bastante quebradiços, gametófitos algumas vezes ramificados, ápice agudo ou levemente acuminado; aletas de tamanhos desiguais, sendo uma bem maior do que a outra e pelas células da lâmina sem perfuraçôes na parede.

Habitat: Na sombra, sobre pedras, rochas úmidas, próximos a rios ou naquelas que recebem respingos de quedas d'água; frestas de rochas, cavernas, em locais mais secos (Yano, 1992).

Distribuiçãoo geográfica: AC, AM, BA, CE, ES, GO, MG, MS, MT, PA, PR, RJ, RO, RR, SE, SP, TO.

Material examinado. BRASIL. Pará: Município de Melgaço, FLONA de Caxiuaná, Estação Científica Ferreira Penna, inventário 8, ao lado da torre, floresta de terra firme, sobre árvore de no 490, 29.IV.1995, R. Lisboa, et al. 4974 (MG); ibidem, Igarapé Grande, floresta de terra firme, sobre árvore viva de no 58, 14.VI.1995, R. Lisboa 5444 (MG); ibidem, Igarapé Curuá, mata de igapó, sobre árvore na margem, 20.X.2004, E. Moraes 52 (MG).

Octoblepharum costatum H.A.Crum, Nova Hedwigia 38: 54. f. 3. 1983.

Descrição e ilustração: Yano (1992). (Figura 1).

Descrição detalhada: Gametófitos 20-25 mm de altura, verde-álbidos quando secos, às vezes rosados até purpúreos. Filídios eretos, laxo-patentes, longo-ligulados, com uma tênue linha rosada da aleta para cima no meio da costa, $12-15 \mathrm{~mm}$ de comprimento, 0,5-0,6 mm de largura. Ápice abruptamente apiculado, margem superior e ápice serrulados. Vista superficial do filídio: células do ápice, regiáo mediana e base retangulares. Corte transversal da costa: ápice $2(1 \mathrm{e}$ 1), regiáo mediana 4 (2 e 2), base 4-5 (2 e 2-3) camadas de leucocistos. Lâminas (aletas) curto-oblongas com 18 fileiras de células leucocísticas, apresentando algumas vezes 2 camadas de células em uma das aletas. Esporófito não observado, mas descrito em Yano (1992).

Comentários: A principal característica é a costa tênue e rosada composta de células sem espessamentos que ocorre como uma linha mediana no filídio.

Habitat: Cresce em lugares úmidos e sombrios de florestas. Em Caxiuanã foi coletada apenas uma única vez sobre tronco em decomposição.

Distribuição geográfica: RJ. Referida como nova ocorrência para o Estado do Pará e Amazônia Brasileira.

Material examinado. BRASIL. Pará: Município de Melgaço, FLONA de Caxiuanã, Estação Científica Ferreira Penna, Igarapé Curuá, plot 1 do TEAM, na trilha, na linha $5 / 450$, floresta de terra firme, sobre tronco em decomposição, 18.X.2004, E. Moraes 38 (MG).

Octoblepharum cylindricum Schimp. ex Mont. Annis Sci. Nat. Bot. sér. 2. 14: 349. 1840.

Descrição e ilustração: Yano (1992).

Comentários: É muito parecida com O. albidum Hedw, diferindo desta pelo ápice do filídio não denteado (inteiro), e base geralmente de cor avermelhada. A espécie quando fértil apresenta a seta característicamente longa e a cápsula cilindrica (Yano, 1992). 
ACTA

AMAZONICA
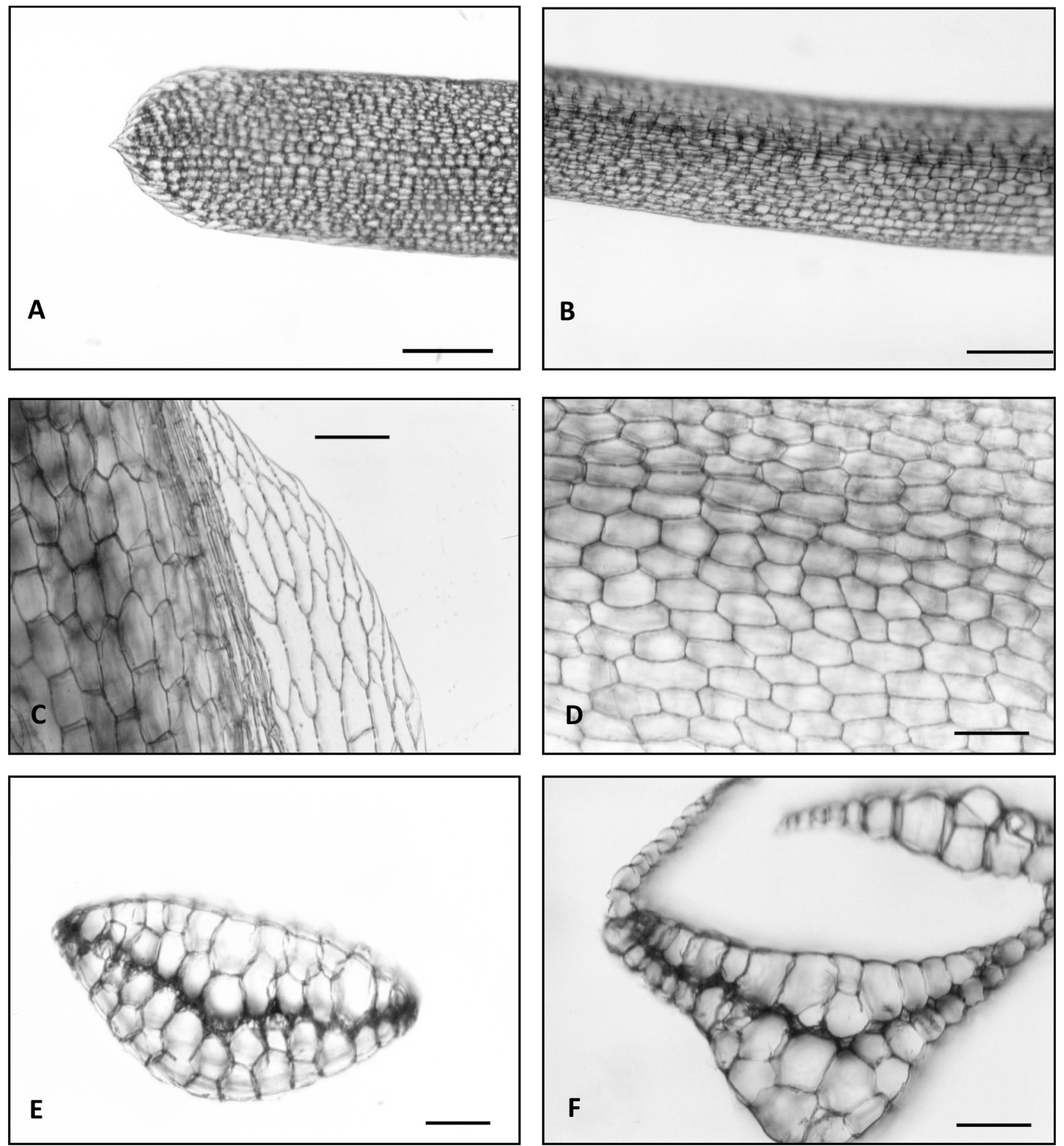

Figura 1- Octoblepharum costatum H.A.Crum -E. Moraes, 38 (MG). A. Ápice do filídio; B. Filídio evidenciando a tênue linha rosada; C. Base do filídio; D. Células medianas do filídio; E. Corte transversal da região mediana do filídio; F. Corte transversal da região basal do filídio (Fotos E. N. R. Moraes, 2006); Escalas A = $270 \mu \mathrm{m} ; \mathrm{B}=850 \mu \mathrm{m} ; \mathrm{C}, \mathrm{D}, \mathrm{F}=140 \mu \mathrm{m} ; \mathrm{E}=100 \mu \mathrm{m}$. 
Habitat: Cresce geralmente formando tapetes no solo arenoso de campinas ou campinaranas, pode ocorrer sobre húmus na base dos troncos de árvores da campina. No cerrado é encontrada em rochas e pedras na proximidade de rios e cachoeiras (Yano, 1992).

Distribuição geográfica: AM, AP, BA, CE, DF, GO, MG, MS, MT, PA, PB, PI, RO, RR, SP e TO.

Material examinado. BRASIL. Pará: Município de Melgaço, FLONA de Caxiuanã, Estação Científica Ferreira Penna, mata próximo à estação, floresta de terra firme, sobre pau podre caído, 9.X.1993, R. Lisboa, R. Bahia \& M. Silva 2390 (MG); ibidem, sobre árvore de Leguminosa, 9.X.1993, R. Lisboa, R. Bahia \& M. Silva 2397 (MG); ibidem, sobre Rubiaceae 9.X.1993, R. Lisboa, R. Bahia \& M. Silva 2404 (MG).

Octoblepharum pulvinatum (Dozy \& Molk.) Mitt., J. Linn. Soc. Bot. 12: 109. 1869.

Descrição e ilustração: Yano (1992) e Peralta (2005).

Comentários: Filídios muito quebradiços quando secos, ápice obtuso, com células isodiamétricas, aletas arredondadas e desiguais, sendo um dos lados maior, com células irregulares; quando fértil os dentes peristomiais apresentam-se afilados e aos pares.

Habitat: Freqüênte na região amazônica, sobre tronco de árvores vivas, em decomposição; base de raízes e troncos de palmeiras; sobre pedras. A espécie é freqüente na área de estudo.

Distribuição geográfica: AC, AM, AP, BA, CE, ES, GO, MA, MG, MS, MT, PA, PE, RJ, RO, RR, SC, SP e TO.

Material examinado. BRASIL. Pará: Município de Melgaço, FLONA de Caxiuanã, Estação Científica Ferreira Penna, Igarapé Curuá, Plot 1 central perto da árvore de $\mathrm{n}^{\circ}$ 14, floresta de terra firme, sobre tronco em decomposiçáo em cupinzeiro, 18.X.2004, E. Moraes 42 (MG); ibidem, Igarapé Curuá, mata de igapó, sobre tronco de árvore viva na margem, 20.X.2004, E. Moraes 46 (MG); ibidem, Igarapé Arauá, plot 4 do TEAM, na trilha, capoeira, sobre caule perto do solo, 22.X.2004, E. Moraes 106 (MG).

\section{DISCUSSÃO}

Considerando as espécies aqui tratadas, as famílias com maior riqueza específica foram Calymperaceae com 23 espécies, Leucobryaceae com 10, Fissidentaceae com 6 e Hypnaceae com 5. Quanto ao número de ocorrências destacaram-se Leucobryaceae (463), Calymperaceae (443) e Fissidentaceae (160), as quais são representativas em toda regiáo amazônica de acordo com os trabalhos de Ilkiu-Borges et al., (2004); Lisboa et al., (1999); Lisboa \& Ilkiu-Borges (2001); Santos \& Lisboa (2003); Souza \& Lisboa (2005). Gradstein \& Pócs
(1989) incluem essas famílias entre as 15 detentoras de $90 \%$ das espécies que ocorrem nas florestas tropicais.

As espécies mais frequentes foram Calymperes lonchophyllum (163), Leucobryum martianum (160), Octoblepharum pulvinatum (138), Syrrhopodon incompletus (95) e Octoblepharum albidum (72). Os substratos preferenciais foram corticícolo e epíxilo, seguido do terrestre e cupinzeiro. Calymperes lonchophyllum, Fissidens pellucidus, Fissidens prionodes, Isopterigium tenerum, I. subbrevisetum e Leucobryum martianum, foram as que se apresentaram sobre uma maior variedade de substratos.

A maioria das espécies predominaram em ambientes úmidos e sombreados como a mata de terra firme, várzea e igapó e poucas estiveram presentes em áreas diretamente expostas ao sol como capoeira e campina. Fato que sustenta a hipótese de que a diversidade dos musgos depende da umidade (Gradstein \& Pócs, 1989).

Os táxons que ocorreram em quatro ou mais formaçóes vegetais foram Calymperes lonchophyllum, C. platyloma, Syrrhopodon incompletus, Fissidens pellucidus, Isopterygium tenerum, Leucobryum martianum, Octoblepharum albidum var. albidum, O. albidum var. violascens. Sendo Calymperes erosum, Octoblepharum pulvinatum, coletados em todos os ecossistemas estudados.

De acordo com Koponen (1978) os dados ecológicos em Briologia são de grande valia, pois ajudam na identificação das espécies. Vale ressaltar que as briófitas são afetadas em larga escala quando há distúrbios e perturbaçóes nos ecossistemas das florestas tropicais. Considerando o fato de serem plantas relativamente pequenas, podem ser efetivamente protegidas apenas pela conservação de seu hábitat (Shaw \& Goffinet, 2000).

As espécies encontradas na área pertencente à Estação Científica Ferreira Penna, estão amplamente distribuídas no país podendo ser encontradas geralmente em quatro ou nas cinco regiôes geográficas. A diversidade encontrada na ECFPn foi expressiva, com relação ao número de espécies ocorrentes para o Estado do Pará. Entretanto náo se pode considerar que o número de espécies encontradas neste trabalho correspondam ao total de musgos para ECFPn.

\section{AGRADECIMENTOS}

As autoras agradecem ao MPEG / UFRA e ECFPn pelo apoio logístico e espaço físico concedido, a Dra. Anna Luiza Ilkiu-Borges pela elaboração do abstract. A primeira autora agradece a CAPES pela bolsa concedida. 


\section{BIBLIOGRAFIA CITADA}

Almeida, S.S.; Lisboa, P.L.B. \& Silva, A.S.L. 1993. Diversidade Floristíca de uma Comunidade Arbórea na Estação Científica Ferreira Penna em Caxiuanã (Pará). Boletim do Museu Paraense Emílio Goeldi, sér. Bot. 9(1): 93-128.

Ando, H. \& Matsuo, A. 1984. Applied bryology. In: Schutze-Motel, W. (Ed.). Advances in Bryology 2. Lehre: J. Cramer. p.133-230.

Bartram, E.B. 1949. Mosses of Guatemala. Fieldiana Botany 25: $1-442$.

Brasil. 1974. Departamento Nacional da Produção Mineral Projeto RADAM. Folha A.S.22 - Belém: geologia, geomorfologia, solos, vegetação e uso potencial da terra. Rio de Janeiro. 480pp. (Levantamento de Recursos Naturais, 5).

Bridel, S. 1826-1827. Bryologia Universa. Leipzig.

Buck, W.R. \& Goffinet, B. 2000. Morphology and Classification of Mosses. In: Shaw, A.J.; Goffinet, B. Bryophyte Biology. Cambridge: University Press Cambridge. cap. 3. p.71-123.

Câmara, P.E.A.S. 2002. Levantamento da brioflora das matas de galeria da reserva Ecológica do IBGE, RECOR. Dissertação de Mestrado, Distrito Federal. UNB, Brasília. 106p.

Câmara, P.E.A.S., Teixeira, R., Lima, J. \& Lima, J. 2003. Musgos urbanos do Recanto das Emas, Distrito Federal, Brasil. Acta Botanica Brasilica 17(4): 507-513.

Castro, N.M.C.F., Pôrto, K.C., Yano, O., Castro, A.A.J.F. 2002. Levantamento florístico de Bryopsida de cerrado e mata ripícula do Parque Nacional de Sete Cidades, Piauí, Brasil. Acta Botanica Brasilica 6(1): 61-76.

Churchill, S.P. 1998. Catalog of Amazonian Mosses. Journal of the Hattori Botanical Laboratory 85: 191-238.

Churchill, S.P. \& Linares, C.E.L. 1995. Prodomus Bryologiae NovoGranatensis: Introduccion a la Flora de Musgos de Colombia. Biblioteca Jose Jeronimo Triana 12: p.105-134.

Costa, D.P. 1988. Leucobryaceae do Parque Nacional da Tijuca, Estado do Rio de Janeiro (Brasil). Rodriguésia 64/66(41/40): 41-48.

Costa, D.P. 2003. Floristic Composition and Diversity of Amazonian Rainforest Bryophytes in the State of Acre, Brazil. Acta Amazonica 33(3): 339-414.

Costa, D.P. \& Silva, A.G. 2003. Briófitas da Reserva Natural da Vale do Rio Doce, Linhares, Espírito Santo, Brasil. Boletim Museu de Biologia Mello Leitão 16: 21-38.

Costa, J.P.R. \& Moraes, J.C. 2002. Médias mensais de variáveis metereológicas. In: Lisboa, P.L.B. (org.). Caxiuanã. Belém, Museu Paraense Emílio Goeldi. p.225-232.

Crum, H.A. \& Anderson, L.E. 1981. Mosses of Easten North America. New York, Columbia University Press. 1 e 2: 1.328pp.

Edwards, S.R.A 1980. Revision of west tropical African Calymperaceae I. Introduction and Calymperes. Journal Bryology 11: 49-93.

Egunyomi, A. 1979. Autecology of Octoblepharum albidum Hedw. in western Nigeria II. Phenology and water relations. Nova Hedwigia 31(1-2): 377-387.
Frahm, J.P. \& Kirchhoff, K. 2002. Antifeeding effects of bryophyte extracts from Neckera crispa and Porella obtusata against the slug Arion lusitanicus. Cryptogamie, Bryologie 23(3): 271-275.

Florschütz, P.A. 1964. The Mosses of Suriname. Musci Part I. In: Lanjouw, J. (ed). Flora of Suriname. Leiden, Brill. p.1-271.

Florschütz-de Waard, J. 1986. Musci (Part II). Flora of Suriname. Ed. Stoffers, A.L.; Lindeman, J.C. Leiden. p. 274-361.

Florschütz-de Waard, J. 1996. Sematophyllaceae. Musci III. In: Görts-Vanrijn, A.R.A. (Ed.). Flora of the Guianas, Series C: Bryophytes, Fascicle 1. p.384-438.

Florschütz-de Waard, J. \& Veling, K. 1996. Hypnaceae. Musci III. In: Görts-Vanrijn, A.R.A. (ed.). Flora of the Guianas, Series $C$ : Bryophytes, Fascicle 1. p.439-462.

Giulietti, A.M., Harley, R.M., Queiroz, L.P. de., Wanderley, M. das G.L. \& Van-Den-Berg, C. 2005. Biodiversidade e conservação das plantas no Brasil. MEGADIVERSIDADE. (1)1: 52-61. Julho.

Glime, J.M. \& Saxena, D. 1991. Uses of Bryophytes. Today \& Tomorrow's Printers \& Publishers. New Delhi. 100p.

Gradstein, S.R. \& Pócs, T. 1989. Bryophytes. in: Lieth, H. \& M.J.A. Werger (eds.) Tropical Rain Forest Ecosystems. Elseiver Science Publishers, Amsterdam. p 311-325.

Griffin III, D. 1979. Guia preliminar para as briófitas freqüentes em Manaus e adjacências. Acta Amazonica 9(3): 1-67. Suplemento.

Ilkiu-borges, A.L., Tavares, A.C.C. \& Lisboa, R.C.L. 2004. Briófitas da Ilha de Germoplasma, Reservatório de Tucuruí, Pará, Brasil. Acta Botanica Brasilica 18(3): 691-694.

Ireland, R.R. 1992. The moss genus Isopterygium (Hypnaceae) in Latin America. Tropical Bryology 6: 111-132.

Koponen, T. 1978. On the taxonomic value of habitat ecology in mosses In: Geissler, P.; Greene. S.W. (eds). Bryophyte Taxonomy. p. 101-105.

Lemos-Michel, E. 2001. Hepáticas Epifiticas Sobre o Pinheiro Brasileiro no Rio Grande do Sul. Porto Alegre: Ed. Universidade UFRGS, 191 pp.

Lisboa, P.L.B., Silva, A.S.L. da. \& Almeida, S.S. de. 1997. Florística e Estrutura dos Ambientes. In: Lisboa, P.L.B. (Org.). Caxiuanã Museu Paraense Emílio Goeldi. cap 4. p. 163-193.

Lisboa, P.L.B. (org.). 2002. Natureza, homem e manejo de recursos naturais na região de Caxiuanã, Melgaço, Pará. Museu Paraense Emilio Goeldi, Belém. 237pp.

Lisboa, R.C.L. 1993. Musgos Acrocárpicos do Estado de Rondônia. Belém, Museu Paraense Emílio Goeldi, Coleção Adolpho Ducke. 272 pp.

Lisboa, R.C.L. 1994. Adiçôes a Brioflora do Estado do Pará. Boletim do Museu Paraense Emílio Goeldi, ser. Bot. 10(1): 15-42.

Lisboa, R.C.L.; Ilkiu-Borges, A.L. 1995. Diversidade das Briófitas de Belém (PA) e seu Potencial como Indicadoras de Poluição Urbana. Boletim do Museu Paraense Emílio Goeldi, ser. Bot. 11(2): 199-225. 
Lisboa, R.C.L.; Ilkiu-Borges, A.L. 1997. A família Splachnobryaceae (Bryophyta) no Estado do Pará. Boletim do Museu Paraense Emílio Goeldi, ser. Bot. 13(2): 103-111.

Lisboa, R.C.L.; Ilkiu-Borges, A.L. 2001. Briófitas de São Luís do Tapajós, Município de Itaituba, com Novas Adições para o Estado do Pará. Boletim do Museu Paraense Emílio Goeldi, ser. Bot. 17(1): 75-91.

Lisboa, R.C.L.; Ilkiu-Borges, A.L. 2007. Uma Nova Avaliação da Brioflora da Reserva do Mocambo, Belém (PA) In: Gomes, J.I. (Org.). História Natural e Biologia da área de Pesquisa Ecológica do Guamá-Apeg. Belém: MPEG: EMBRAPA

Lisboa, R.C.L. \& Ilkiu-Borges, F. 1996. Briófitas da Serra dos Carajás e sua possível utilizaçáo como indicadoras de metais. Boletim do Museu Paraense Emílio Goeldi, ser. Bot. 12(2): 161-181.

Lisboa, R.C.L. \& Lima, M.J.L. de. 1997. Leucophanaceae, nova família de Bryophyta para o Pará, Brasil. Acta Botanica Brasilica 11(1): 79-85.

Lisboa, R.C.L., Lima, M.J.L. de. \& Maciel, U.N. 1999. Musgos da Ilha de Marajó-II- Anajás Pará, Brasil. Acta Amazonica 29(2): 201-206.

Lisboa, R.C.L. \& Maciel, U.N. 1994. Musgos da Ilha de Marajó-IAfuá, Pará. Boletim Museu Paraense Emílio Goeldi, ser. Bot. 10(1): 43-56.

Lisboa, R.C.L., Muniz, A.C.M. \& Maciel, U.N. 1998. Musgos da Ilha de Marajó-III- Chaves (Pará). Boletim do Museu Paraense Emílio Goeldi, ser. Bot. (14)2: 117-125.

Lisboa, R.C.L. \& Nazaré, J.M.M. de. 1997. A Flora Briológica. In: Lisboa, P.L.B. (Org.). Caxiuanã. Belém: CNPq/MPEG, cap. 4. p.223-235.

Lisboa, R.C.L. \& Nazaré, J.M.M. de. 2002. A Familia Sematophyllaceae (Bryophyta) - Novas Adiçôes. In: Lisboa, P.L.B. (Org.). Caxiuanã: Populaçóes tradicionais, meio físico e diversidade biológica. Belém: Museu Paraense Emílio Goeldi. cap. 5. p.389-397.

Luizi-Ponzo, A.P. (coord.), Bastos, C.J.P., Costa, D.P., Pôrto, K.C., Câmara, P.E.S.A., Lisboa, R.C.L. \& Villas Bôas-Bastos, S. 2006. Glossarium Polyglottum Bryologiae: Versão Brasileira do Glossário Briológico. Juiz de Fora: Ed. UFJF, 114 pp.

Molinaro, L.de C. \& Costa, D.P. da. 2001. Briófitas do Arboreto do Jardim Botânico do Rio de Janeiro. Rodriguésia. 52(51): 107-124.

Moraes, E.N.R. 2006. Diversidade, aspectos florísticos e ecológicos dos musgos (Bryophyta) da Estação Cientifica Ferreira Penna, Flona de Caxiuanã, Pará, Brasil. Dissertaçáo de Mestrado. Universidade Federal Rural da Amazônia/Museu Paraense Emílío Goeldi, PA. 149 p.

Moraes, E.N.R. \& Lisboa, R.C.L. 2006. Musgos (Bryophyta) da Serra dos Carajás, Estado do Pará, Brasil. Boletim do Museu Paraense Emilio Goeldi, série Ciências Naturais, Belém, 1:(1): p.39-68.

Ochi, H. 1980. A revision of the Neotropical Bryoidae Musci (First Part). The Journal of the Faculty of Education Tottori University 29 (2):1-154.
Oliveira-e-Silva, M.I.M.N. \& Yano, O. 2000. Musgos de Mangaratiba e Angra dos Reis, Rio de Janeiro, Brasil. Boletim do Instituto de Botânica 4(14): 1-137.

Peralta, D.F. 2005 Musgos (Bryophyta) do Parque Estadual da Ilha Anchieta (PEIA), São Paulo, Brasil. Dissertação de Mestrado. Instituto de Botânica da Secretaria de Estado do Meio Ambiente. São Paulo. 227 p.

Pôrto, K.C., Cabral, J.J.P. \& Tabarelli, M. (orgs.). 2004. Brejos de Altitude em Pernambuco e Paraíba. História Natural, Ecologia e Conservação. Brasília: Ministério do Meio Ambiente, Série biodiversidade 9: 324.

Pursell, R.A. 1984. A preliminary study of the Fissidens elegans complex in the neotropics. Journal Hattori Botanical Laboratory 55: 235-252.

Pursell, R.A. 1997. Taxonomic Notes on Neotropical Fissidens. II. An Addendum. The Bryologist 100(2): 193-197.

Reese, W.D. 1961. The genus Calymperes in the Americas. The Bryologist 64(2/3): 89-140.

Reese, W.D. 1978. The genus Syrrhopodon in the Americas II. The Limbate species. The Bryologist 81(2): 189-225.

Reese, W.D. 1979. Calymperaceae (Musci) from western Amazonia: Brazil and Bolivia. The Bryologist 82(2): 559-563.

Reese, W.D. 1981. Refinements on American Syrrhopodon (Musci, Calymperaceae). The Bryologist 84: 244-248.

Reese, W.D. 1993. Calymperaceae. Flora Neotropica. monograph 58. New York, Botanical Garden. 102 p.

Reese, W.D. 1995. Synopsis of Syrrhopodon Subgenus Pseudocalymperes. The Bryologist 98(1): 141-145.

Reese, W.D.; Griffin III, D. 1977. Noteworthy Calymperaceae from Brazil and Venezuela. Acta Amazonica 7(2): 179-184.

Reese, W.D. \& Stone, I.G. 1995. The Calymperaceae of Australia. Journal Hattori Botanical Laboratory 78: 1-40.

Robbins, R.G. 1952. Bryophyta Ecology of a Dune Area in New Zealand. Vegetation, Acta Geobotanica 4: 1-131.

Ruivo, M. de L.P., Quantz, B., Sales, M.E. da C \& Meir, P. 2002. Solos dos sítios do experimento, Esecaflor. In: Lisboa, P.L.B. (Org.). Caxiuanã: Populaçôes Tradicionais, Meio Físico e Diversidade Biológica. Belém: Museu Paraense Emílio Goeldi, cap.3. p. 207-213.

Santos, R.C.P. \& Lisboa, R.C.L. 2003. Musgos (Bryophyta) do Nordeste Paraense, Brasil - 1. Zona Bragantina, microrregião do Salgado e município de Viseu. Acta Amazônica 33(3): 415422.

Schofield, W.B. 1985. Introducion to Bryology. New York: MacMillan Publishing. 413pp.

Sharp, A.J., Crum, H. \& Eckel, P.M. 1994. The Moss Flora of México. Memoirs of The New York Botanical Garden 69(1-2): $1-1113$.

Shaw, A.J. \& Goffinet, B. (Eds.). 2000. Bryophyte Biology. Cambridge: University Press Cambridge. 476 pp. 
Souza, A.P.S. 2004. Inventário de Musgos (Bryophyta) do Município de Barcarena (PA) Brasil. Dissertação de Mestrado. Universidade Federal Rural da Amazônia (UFRA). Belém. 137p.

Souza, A.P.S. \& Lisboa, R.C.L. 2005. Musgos (Bryophyta) na Ilha Trambioca, Barcarena, PA. Acta Botanica Brasilica 19(3): 487-492.

Spence, J. R. \& H. P. Ramsay 2005. New genera and combinations in the Bryaceae (Bryales, Musci) for Australia. Phytologia 87: 61-72.

Veling, K. 1996. Leucomiaceae. Musci III. In: A.R.A. Görts-Van Rijn (ed.). Flora of the Guianas. Series C: Bryophytes, Fascicle 1. p.365-370.

Visnadi, S.R. 2002. Meteoriaceae (Bryophyta) da Mata Atlântica do estado de São Paulo. Hohenea 29: 159-187.

Visnadi, S.R. 2004. Distribuição da brioflora em diferentes fisionomias de cerrado da Reserva Biológica e Estação Experimental de Mogi-Guaçu, SP, Brasil. Acta Botanica Brasilica 18(4): 965-973.

Visnadi, S.R. 2005. Brioflora da Mata Atlântica do estado de São Paulo: região norte. Hohenea 32(2): 215-231.

Vitt, D.H. 1984. Classification of the Bryopsida. In: Shuster, R.W. (Ed.) - New Manual of Bryology. Nichinan. Journal Hattori Botanical Laboratory 2: 696-759.

Yano, O. 1981. Contribuição ao inventário dos Musci brasileiros: 2. Phyllodrepaniaceae. Acta Amazônica 11(3): 505-509.

Yano, O. 1982. Distribuição geográfica de Leucobryaceae (Bryopsida) na Amazônia. Acta Amazonica 12(2): 307-321.

Yano, O. 1989. An Additional Checklist of Brazilian Bryophytes. The Journal Hattori Botanical Laboratory 66: 371-434.

Yano, O. 1992. Leucobryaceae (Bryopsida) do Brasil. Tese de Doutorado. Universidade de São Paulo. 318p.
Yano, O. 1994. Briófitas da Serra da Itabaiana, Sergipe, Brasil. Acta Botanica Brasilica 8(1): 45-57.

Yano, O. 1995. A New Additional Checklist of Brazilian Bryophytes. The Journal Hattori Botanical Laboratory 78: 137-182.

Yano, O. 2004. Novas ocorrências de briófitas para vários estados do Brasil. Acta Amazonica, 34(4): 559-576.

Yano, O. \& Bastos, C.J.P. 1994. Musgos do estado da Bahia, Brasil. Biologica Brasílica 6(1-2): 9-26.

Yano, O. \& Camara, P.E.A.S. 2004. Briófitas de Manaus, Amazonas, Brasil. Acta Amazonica 34(3): 445-457.

Yano, O. \& Colletes, A.G. 2000.Briófitas do Parque Nacional de Sete Quedas, Guairá, PR, Brasil. Acta Botanica Brasilica 14(2): 215-242.

Yano, O. \& Peralta, D.F. 2004. Musgos (Bryophyta) de Mato Grosso, Brasil. Hoehnea 31(3): 251-292.

Yano, O. \& Oliveira-e-Silva, M.I.M.N. 1997. Criptógamos do Parque Estadual das fontes do Ipiranga, São Paulo, SP. Briófitas, 2: Fissidentaceae (Bryales). Hoehnea 24(2): 107-114.

Yano, O. \& Peralta, D. F. 2008. Briófitas da Ilhabela, Estado de São Paulo, Brasil. Hoehnea 35: 111-121.

Zartman, C.E. 2003. Habitat Fragmentation Impacts on Epiphyllous Bryophyte Communities in Central Amazonia. Ecology 84(4): 949-954.

Zielman, H.R. 1996. Thuidiaceae. Musci III. In: AR.A. Görts-Van Rijn (ed.). Flora of the Guianas. Series C: Bryophytes, Fascicle 1. p.371-383.

Recebido em 22/11/2007

Aceito em 08/08/2009 
ACTA

AMAZONICA

Diversidade, taxonomia e distribuição por estados brasileiros das famílias Bartramiaceae,

Brachytheciaceae, Bryaceae, Calymperaceae, Fissidentaceae, Hypnaceae e Leucobryaceae (Bryophyta) da Estação Científica Ferreira Penna, Caxiuanã, Pará, Brasil 